\title{
Inhibitive properties, thermodynamic, kinetics and quantum chemical calculations of polydentate Schiff base compounds as corrosion inhibitors for iron in acidic and alkaline media
}

\author{
Loutfy H. Madkour ${ }^{1}\left[\right.$ · S. K. Elroby ${ }^{2}$
}

Received: 12 November 2014/ Accepted: 7 May 2015/Published online: 20 May 2015

(c) The Author(s) 2015. This article is published with open access at Springerlink.com

\begin{abstract}
Quantum chemical calculations based on the density functional theory (DFT) method were performed on five polydentate Schiff base compounds (PSCs), act as corrosion inhibitors for iron in aerated $2.0 \mathrm{M} \mathrm{HNO}_{3}$ and $2.0 \mathrm{M} \mathrm{NaOH}$, aiming to analyze the characteristics of the inhibitor/surface mechanism as well as to analyze the experimental data and to describe the structural nature of the inhibitor on the corrosion process. The relationship between molecular structure of PSC and their inhibition efficiencies was discussed. The inhibition effect has been investigated using weight loss, thermometric, potentiodynamic polarization measurements and quantum chemical study. Among the compounds studied, 4-(2-hydroxynaphthylideneamino) antipyrine (PSC_1) exhibited the best inhibition efficiency IE (\%) $78.4 \%$ at $10^{-4} \mathrm{M}$ at $303 \mathrm{~K}$. The high IE of (PSCs) was attributed to the blocking of active sites by adsorption of inhibitor molecules on the iron surface. Adsorption of (PSCs) inhibitors is spontaneous, exothermic, obeyed Temkin isotherm and is regarded as physiochemical mechanism. Polarization measurements indicate that all the examined Schiff bases are of mixedtype inhibitor in $\mathrm{HNO}_{3}$; causing only inhibition of the cathode process in $\mathrm{NaOH}$. The results showed that the inhibition efficiency of PSCs increased with the increase in $\mathrm{E}_{\mathrm{HOMO}}$ and decrease in $E_{\mathrm{LUMO}}-E_{\mathrm{HOMO}}$; and the areas containing $\mathrm{N}$ and $\mathrm{O}$ atoms are most possible sites for
\end{abstract}

Loutfy H. Madkour

loutfy_madkour@yahoo.com

1 Chemistry Department, Faculty of Science and Arts, Baljarashi, Al-Baha University, P.O. Box 1988, Al-Baha, Saudi Arabia

2 Chemistry Department, Faculty of Science, King Abdul-Aziz University, P.O. Box 80203, Jeddah 21589, Saudi Arabia bonding the metal iron surface by donating electrons to the metal.

Keywords Inhibition corrosion - DFT method - Schiff bases · Kinetics · Iron · Temkin isotherm

\section{Introduction}

Recently, Schiff base compounds have been of interest to obtain efficient corrosion inhibitors since they provide much greater inhibition by adsorption on metal surface compared with corresponding amines and aldehydes [1-4]. The presence of the $-\mathrm{C}=\mathrm{N}-$ group in Schiff base molecules enhances their adsorption ability and corrosion inhibition efficiency [5, 6]. Recent publications show increased attention to these compounds as corrosion inhibitors in typically acidic environments for various metals like iron, steel, aluminum and copper [7-9]. Schiff bases are conveniently and easily synthesized from relatively cheap material. Some polydentate Schiff base compounds (PSCs) containing aminic nitrogen have been found to be good inhibitors for mild steel in acidic medium [4]. Theoretical chemistry has been used recently to explain the mechanism of corrosion inhibition, such as quantum chemical calculations [10-12]. Quantum chemical calculations have been proved to be a very powerful tool for studying the mechanism [13]. Previously, some work has been done in our laboratory on Schiff bases [14]. The objective of this work was undertaken to investigate the inhibition of corrosion of iron in $\mathrm{HNO}_{3}$ and $\mathrm{NaOH}$ by five PSCs to present a theoretical study on electronic and molecular structures of aminic nitrogen-containing PSCs and to determine relationship between molecular structure of the PSCs inhibitors and inhibition efficiency. The structural quantum 
parameters, such as the frontier molecular orbital energy HOMO (highest occupied molecular orbital) and LUMO (lowest unoccupied molecular orbital), have been calculated, discussed and correlated with inhibition efficiencies.

\section{Experimental method}

\section{Materials and chemicals}

The investigated Schiff bases (PSCs) were prepared from 1:1 mol ratios of amine with the optimum salicylaldehyde and/or benzyl aldehyde through a condensation reaction in ethanoic media in a reflux condenser for $4 \mathrm{~h}$. The solution was further concentrated, cooled in ice bath and the compound formed. The products were recrystallized twice from ethanol, washed by water and dried under vacuum to afford pale yellow crystals $[14,15]$. The molecular structure of the synthesized Schiff base was determined by chemical analyses for the atoms, IR, UV-visible spectroscopic investigation; and mass spectroscopy techniques. The chemical structure and IUPAC name of synthesized compounds are given in Fig. 1. The corrosion tests were performed on iron specimens of the following composition (wt\%): $\mathrm{C}=0.16$, $\mathrm{Mn}=0.37, \mathrm{Si}=0.05, \mathrm{~S}=0.015$ and remainder Fe. Iron specimens of size $2.0 \times 2.0 \times 0.1$ and $10 \times 1 \times 0.1 \mathrm{~cm}$ were used for weight loss and thermometric measurements, respectively. Solution of $2.0 \mathrm{M} \mathrm{HNO}_{3}$ and $2.0 \mathrm{M} \mathrm{NaOH}$ was prepared by dilution of Analar analytical grade using double distilled water. The concentration range of (PSCs) inhibitors employed was $5 \times 10^{-7} \mathrm{M}-10^{-4} \mathrm{M}$ at $303 \mathrm{~K}$.

\section{Measurements}

\section{Weight loss measurements}

Weight loss experiment experiments were done according to the standard methods as reported in literature [16]. The corrosion rates $C_{\mathrm{R}}\left(\mathrm{mg} \mathrm{cm}^{-2} \mathrm{~h}^{-1}\right)$ were calculated according to the following equation $[17,18]$ :

$\mathrm{CR}=(\mathrm{Wb}-\mathrm{Wa}) / A t$

where $\mathrm{Wb}$ and $\mathrm{Wa}$ are coupon weights measured before and after immersion in the test solutions, $A$ is the exposed area and $t$ is the exposure time $(6 \mathrm{~h})$.

The inhibition efficiency IE (\%) was calculated according to the following equation [19]:

$\operatorname{IE}(\%)=\frac{C_{\mathrm{R}}-C_{\mathrm{R}}(\mathrm{inh})}{C_{\mathrm{R}}} \times 100$

where $C_{\mathrm{R}}$ and $C_{\mathrm{R}}$ (inh) are the values of corrosion rate $\left(\mathrm{mg} \mathrm{cm}{ }^{-2} \mathrm{~h}^{-1}\right)$ of iron in uninhibited and inhibited solutions, respectively.<smiles>Cc1c(N=Cc2c(O)ccc3ccccc23)c(=O)n(-c2ccccc2)n1C</smiles>

4-(2-Hydroxynaphthylideneamino) antipyrine (PSC_1)<smiles>Cc1c(/N=C/c2ccccc2O)c(=O)n(-c2ccccc2)n1[N+](=O)[O-]</smiles>

4-(2-Hydroxybenzylideneamino) antipyrine (PSC_2)

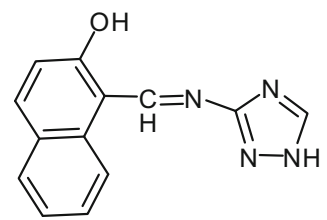

3-(2-Hydroxynaphthylideneamino)-1,2,4-triazole (PSC_3)

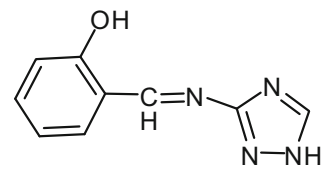

3-(2-Hydroxybenzylideneamino)-1,2,4-triazole (PSC_4)

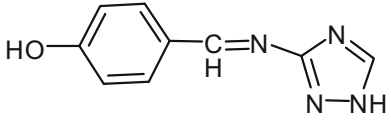

3-(4-Hydroxybenzylideneamino)-1,2,4-triazole (PSC_5)

Fig. 1 Chemical structure of the investigated polydentate Schiff base compounds PSCs (1-5)

\section{Thermometric measurements}

The reaction vessel used was basically the same as that described by Mylius [20]. An iron piece $(10 \times 1 \times 0.1 \mathrm{~cm})$ was immersed in $30 \mathrm{~cm}^{3}$ of either $2.0 \mathrm{M} \mathrm{HNO}_{3}$ and/or $2.0 \mathrm{M} \mathrm{NaOH}$ in the absence and presence of additives, and the temperature of the system was followed as a function of time. The procedure for the determination of the metal dissolution rate by the thermometric method has been described previously $[20,21]$. The reaction number $(\mathrm{RN})$ is defined [22] as: 
$\mathrm{RN}=\frac{\left(T_{\max }-T_{i}\right)}{t}$

where $T_{\max }$ and $T_{i}$, are the maximum and initial temperatures, respectively, and $t$ is the time (in minutes) required to reach the maximum temperature. The percent reduction in $\mathrm{RN}$ [23] is then given as:

$\%$ Reduction in $\mathrm{RN}=\frac{(\mathrm{RN} \text { free }-\mathrm{RN} \text { inh })}{\mathrm{RN} \text { free }} \times 100$

\section{Electrochemical measurements}

A conventional three-electrode cell was used with a $1.0 \mathrm{~cm}^{2} \mathrm{Pt}$ sheet as the counter electrode which was separated from the main cell compartment by a glass sinter. The potentials of the working electrode were referred to a saturated calomel electrode (SCE). To avoid contamination, the reference electrode was connected to the working electrode through a salt bridge filled with the test solution. The tip of the bridge was pressed against the working electrode to compensate the ohmic drop. Prior to each experimental measurement, the solution under investigation $\left(25 \mathrm{~cm}^{3}\right)$ was freed of oxygen by passing prewashed pure nitrogen through it for a sufficient time. Measurements were performed on a planar disk electrode $\left(A=1 \mathrm{~cm}^{2}\right)$. The iron electrodes were carefully degreased, and the edges were masked by appropriate resins (Duracryle, Spofa-Dental, and Praha). The surface of the iron electrodes was prepared by mechanical grinding and polishing as given elsewhere [24, 25]. The electrodes were rinsed in an ultrasonic bath containing bid stilled water and finally washed with bid stilled water immediately before being immersed in the cell. The pretreatment procedure was repeated before each experiment. Anodic and cathodic potentiostatic polarization of iron electrodes was measured with a Wenking Potentioscan model POS 73. Potentials and currents were determined by digital multi meters. Corrosion current densities $\left(I_{\text {corr }}\right)$ were determined by extrapolation of the anodic and cathodic Tafel lines to the free corrosion potential value ( $\left.E_{\text {corr }}\right)$. Each experiment was conducted with a freshly prepared solution and with newly polished electrodes. The cell temperature was kept constant at $303.0 \pm 1.0 \mathrm{~K}$ in an ultra-thermostat.

The inhibition efficiencies at different inhibitor concentrations were calculated using the following equation:

$\operatorname{IE}(\%)=\frac{I_{\text {corr }}-I_{\text {corr }}(\text { inh })}{I_{\text {corr }}} \times 100$

where $I_{\text {corr }}$ and $I_{\text {corr }}$ (inh) are the corrosion current densities for uninhibited and inhibited solutions, respectively.

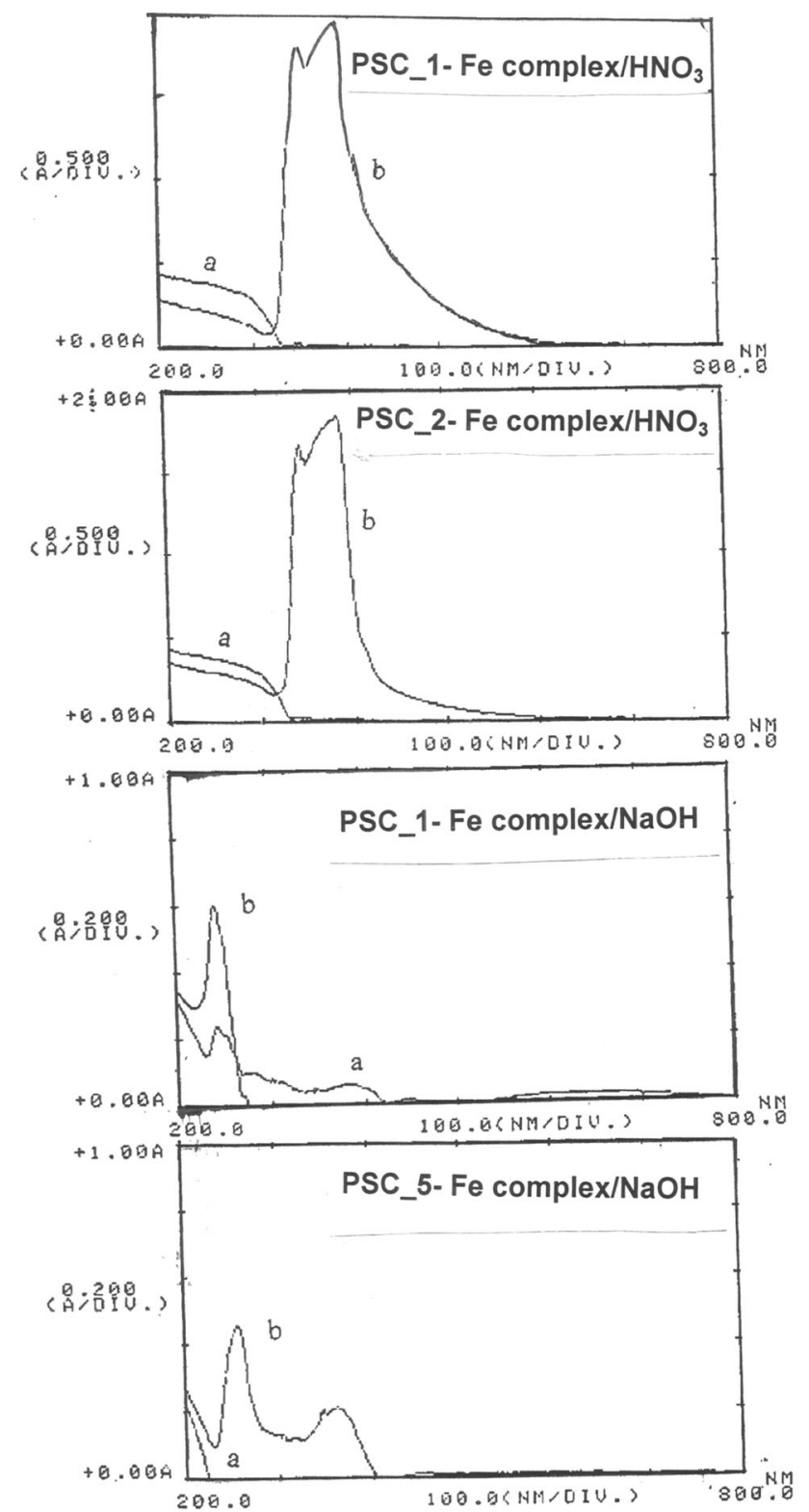

Fig. 2 Absorption spectra of $\mathrm{Fe}$ ions either in $2.0 \mathrm{M} \mathrm{HNO}_{3}$ or $2.0 \mathrm{M}$ $\mathrm{NaOH}$ containing $10^{-4} \mathrm{M}$ PSC_1, PSC_2 and PSC_5: a without inhibitors and b with inhibitors at $303 \mathrm{~K}$

\section{Spectrophotometric measurements}

UV-visible absorption spectrophotometric method was applied on the corrosive solutions produced from the corrosion of iron samples, either without or with PSC_1 and PSC_2 in $2.0 \mathrm{M} \mathrm{HNO}_{3}$; and PSC_1 and PSC_5 in $2.0 \mathrm{M}$ $\mathrm{NaOH}$, respectively. All the spectra measurements were carried out using a Perkin-Elmer UV-Visible Lambda 2 spectrophotometer (Fig. 2). 


\section{Theory and computational details}

Density functional theory (DFT) methods were used in this study. In agreement with the DFT results, energy of the fundamental state of a polyelectronic system can be expressed through the total electronic density and, in fact, the use of electronic density instead of the wave function for calculating the energy constitutes the fundamental base of DFT [26]. The initial geometry optimizations and frequency calculations were done at the Hartree-Fock (HF) level of theory using the standard $6-31 G^{*}$ basis set which requests that a set of $\mathrm{d}$ function be included for each atom heavier and $\mathrm{P}$ function for hydrogen. The HF geometry was later reoptimized using DFT with frequency calculation using 6-31G** basis set. The frequency calculation were carried out to confirm the local structures forms. The calculations were done using the Becke's Three Parameter Hybrid Method (B3) [27] employing the correlation functional of Lee, Yang and Parr (LYP) [28]; including both local and non-local terms. All calculations are performed using the Gaussian09W program [29]. Single point calculations were carried for the optimized structures using B3LYP/6-311++ $\mathrm{G}^{* *}$ level of theory. The natural bonding orbital's' (NBO) calculations [30] were performed using NBO 3.1 program as implemented in the Gaussian 03 package at the DFT/B3LYP/6-311G(d, p) level to explore the charge distribution for the studied compounds.

\section{Results and discussion}

Previously, some work has been done in our laboratory on Schiff base inhibitors on iron [14]. In the present study, the relations between the experimental inhibition efficiency IE (\%), using weight loss, thermometric and electrochemical measurements of the Schiff bases in $2.0 \mathrm{M} \mathrm{HNO}_{3}$ and in $2.0 \mathrm{M} \mathrm{NaOH}$ solutions and some quantum parameters (such as HOMO energy and LUMO energy) have been discussed. Quantum chemical calculations have been proved to be a very powerful tool for studying the mechanism, as well as to analyze the experimental data.

\section{Chemical and electrochemical measurements}

For the chemical methods, a weight loss measurement is ideally suited for long-term immersion test. The thermometric results reported in Table 1 reveal that the inhibition efficiency of the PSC_1 additive (as example) for all (PSCs), as determined from the percentage reduction in $\mathrm{RN}$, increases with increasing concentration of the additives.
According to Ferreira and others [31, 32] if the displacement in $\left(E_{\text {corr }}\right)$ values $(1)>85 \mathrm{mV}$ in inhibited system with respect to uninhibited, the inhibitor could be recognized as cathodic or anodic type and (2) if displacement in $\mathrm{E}_{\text {corr }}$ is $<85 \mathrm{mV}$, it could be recognized as mixed type. For studied (PSCs) inhibitors, the maximum displacement range was 20-60 Mv towards cathodic region, which indicates that all studied (PSCs) are mixed-type inhibitors [33] in the acidic medium. The maximum displacement range was 95$139 \mathrm{mV}$ towards cathodic region in $2.0 \mathrm{M} \mathrm{NaOH}$, which indicates that all studied (PSCs) are cathodic type inhibitors in alkaline medium. The values of corrosion parameters are listed in Table 2. The values of corrosion current density $\left(I_{\text {corr }}\right)$ decreased in the presence of PSCs which suggests that the rate of electrochemical reaction was reduced due to the formation of a barrier layer over the iron surface by the inhibitor molecule. From Table 2, it is also clear that the values of cathodic and anodic Tafel slope constant are slightly changed in the presence of all PSCs. This suggest that studied inhibitors were first adsorbed onto the iron surface and impeded by merely blocking the reaction sites of the metal surface without affecting the anodic and cathodic reaction [34]. Polarization resistance value increases with increasing inhibitor concentration, which suggests the retardation of iron corrosion in inhibited solutions with respect to uninhibited. The anodic dissolution of iron and cathodic reactions in acidic and/or alkaline media has been reported to proceed as follows [35]:

$\mathrm{Fe} \rightarrow \mathrm{Fe}^{2+}+2 \mathrm{e}^{-}$

$2 \mathrm{H}^{+}+2 \mathrm{e}^{-} \rightarrow 2 \mathrm{H}_{\mathrm{ads}} \rightarrow \mathrm{H}_{2}$

$\mathrm{Fe}+\mathrm{OH}^{-} \rightleftarrows \mathrm{FeOH}_{\mathrm{ads}}+\mathrm{H}^{+}+\mathrm{e}^{-}(\mathrm{rds})$

$\mathrm{FeOH}_{\mathrm{ads}} \rightarrow \mathrm{FeOH}^{+}+\mathrm{e}^{-}$

$\mathrm{FeOH}^{+}+\mathrm{H}^{+} \rightleftarrows \mathrm{Fe}^{2+}+\mathrm{H}_{2} \mathrm{O}$

where 'rds' stands for rate-determining step. As a result of these reactions, including the high solubility of the corrosion products, it is evident that the weight loss of iron increases with time. It may also suggest that the iron corrosion by $\mathrm{HNO}_{3}$ and $\mathrm{NaOH}$ is a heterogeneous process involving several steps. The temperature-time curves provide a mean of differentiating between weak and strong adsorption. The thermometric data are depicted in Table 2. It is evident that the dissolution of iron in $2.0 \mathrm{M} \mathrm{HNO}_{3}$ starts from the moment of immersion. On increasing the concentration of the inhibitor from $\left(5 \times 10^{-7}-1 \times 10^{-4}\right.$ M) the value of $T_{\max }$ decreases, whereas the time $(t)$ required reaching $T_{\max }$ increases, and both factors cause a large decrease in (RN) and increase in (\% red RN). This indicates that the studied synthesized PSCs retard the dissolution presumably by strongly adsorption onto the metal 
Table 1 Effect of different concentrations of (PSC_1) on the thermometric parameters of iron in $2.0 \mathrm{M} \mathrm{HNO}_{3}$

\begin{tabular}{llllllllll}
\hline Conc. (M) & $\log C$ & $T_{i}{ }^{\circ} \mathrm{C}$ & $T_{\max }{ }^{\circ} \mathrm{C}$ & $t_{\min }$ & $\Delta t_{\min }$ & $\log \Delta t$ & $\theta$ & $\mathrm{RN}$ & $\%$ Red in RN \\
\hline $2.0 \mathrm{M} \mathrm{HNO}_{3}$ & - & 19.5 & 50.8 & 68 & - & - & - & 0.460 & - \\
$5 \times 10^{-7}$ & -6.3 & 17.8 & 46.8 & 130 & 62 & 1.792 & 0.515 & 0.223 & 51.6 \\
$1 \times 10^{-6}$ & -6.0 & 17.5 & 46.5 & 141 & 73 & 1.863 & 0.554 & 0.205 & 55.4 \\
$5 \times 10^{-6}$ & -5.3 & 17.0 & 45.7 & 155 & 87 & 1.939 & 0.597 & 0.185 & 59.8 \\
$1 \times 10^{-5}$ & -5.0 & 18.0 & 44.1 & 177 & 109 & 2.037 & 0.680 & 0.147 & 68.0 \\
$5 \times 10^{-5}$ & -4.3 & 18.0 & 44.0 & 190 & 122 & 2.086 & 0.702 & 0.136 & 70.3 \\
$1 \times 10^{-4}$ & -4.0 & 18.0 & 41.0 & 200 & 132 & 2.120 & 0.750 & 0.115 & 75.9 \\
\hline
\end{tabular}

Table 2 Polarization parameters and corresponding inhibition efficiency for the iron in $2.0 \mathrm{M} \mathrm{HNO}_{3}$ and $2.0 \mathrm{M} \mathrm{NaOH}$ with and without addition of $1 \times 10^{-4} \mathrm{M}$ PSC_1 at $303 \mathrm{~K}$

\begin{tabular}{|c|c|c|c|c|c|c|c|}
\hline Conc. (M) & Corrosive solution & $-E_{\text {corr }}[\mathrm{mV}(\mathrm{SCE})]$ & $I_{\text {corr }}\left(\mathrm{mA} \mathrm{cm}^{-2}\right)$ & $-\beta_{\mathrm{c}}\left(\mathrm{V} \mathrm{dec}{ }^{-1}\right)$ & $\beta_{\mathrm{a}}\left(\mathrm{V} \mathrm{dec}{ }^{-1}\right)$ & $\theta$ & IE $(\%)$ \\
\hline Blank & $2.0 \mathrm{M} \mathrm{HNO}_{3}$ & 340 & 34.670 & 0.960 & 0.879 & - & - \\
\hline Blank & $2.0 \mathrm{M} \mathrm{NaOH}$ & 775 & 6.762 & 0.350 & - & - & - \\
\hline \multirow[t]{2}{*}{$5 \times 10^{-7}$} & $2.0 \mathrm{M} \mathrm{HNO}_{3}$ & 320 & 12.264 & 0.951 & 0.811 & 0.646 & 64.6 \\
\hline & $2.0 \mathrm{M} \mathrm{NaOH}$ & 725 & 4.844 & 0.334 & - & 0.284 & 28.4 \\
\hline \multirow[t]{2}{*}{$1 \times 10^{-6}$} & $2.0 \mathrm{M} \mathrm{HNO}_{3}$ & 318 & 12.177 & 0.848 & 0.810 & 0.648 & 64.8 \\
\hline & $2.0 \mathrm{M} \mathrm{NaOH}$ & 720 & 4.563 & 0.324 & - & 0.325 & 32.5 \\
\hline \multirow[t]{2}{*}{$5 \times 10^{-6}$} & $2.0 \mathrm{M} \mathrm{HNO}_{3}$ & 300 & 11.985 & 0.844 & 0.774 & 0.654 & 65.4 \\
\hline & $2.0 \mathrm{M} \mathrm{NaOH}$ & 685 & 3.693 & 0.285 & - & 0.453 & 45.3 \\
\hline \multirow[t]{2}{*}{$1 \times 10^{-5}$} & $2.0 \mathrm{M} \mathrm{HNO}_{3}$ & 295 & 11.928 & 0.843 & 0.772 & 0.656 & 65.6 \\
\hline & $2.0 \mathrm{M} \mathrm{NaOH}$ & 673 & 3.362 & 0.267 & - & 0.503 & 50.3 \\
\hline \multirow[t]{2}{*}{$5 \times 10^{-5}$} & $2.0 \mathrm{M} \mathrm{HNO}_{3}$ & 285 & 10.197 & 0.844 & 0.760 & 0.705 & 70.5 \\
\hline & $2.0 \mathrm{M} \mathrm{NaOH}$ & 650 & 3.035 & 0.255 & - & 0.551 & 55.1 \\
\hline \multirow[t]{2}{*}{$1 \times 10^{-4}$} & $2.0 \mathrm{M} \mathrm{HNO}_{3}$ & 280 & 9.078 & 0.841 & 0.754 & 0.738 & 73.8 \\
\hline & $2.0 \mathrm{M} \mathrm{NaOH}$ & 644 & 2.489 & 0.232 & - & 0.632 & 63.2 \\
\hline
\end{tabular}

surface. The extent of inhibition depends on the degree of the surface coverage $(\theta)$ of the iron surface with the adsorbate. Iron, as an active element, always carries an air formed oxide, which specifically and very strongly adsorbs $\mathrm{H}^{+}$and $\mathrm{OH}^{-}$ions according to the Eqs. (8-10). These reactions take place along the incubation period. The heat evolved from the above reactions accelerates further dissolution of the oxide and activates the dissolution of the iron metal exposed to the aggressive medium.

\section{Quantum chemical studies}

Density functional theory is simpler than quantum mechanics. The interest has grown in understanding the structure, properties, reactivity, and dynamics of atoms, molecules and clusters for the study of reaction mechanism [36]. Furthermore, atomic charges are used for the description of the molecular polarity of molecules. Frontier orbital theory is useful in predicting adsorption centers of the inhibitor molecules responsible for the inter-action with surface metal atoms [13]. Terms involving the frontier MO could provide dominative contribution, because of the inverse dependence of stabilization energy on orbital energy difference. Moreover, the gap between the HOMO and LUMO energy levels of the molecules was another important factor that should be considered. Reportedly, excellent corrosion inhibitors are usually those organic compounds who not only offer electrons to unoccupied orbital of the metal, but also accept free electrons from the metal [11]. In the present investigation, quantum chemical calculation using DFT was employed to explain, correlate, confirm and support the experimental results $[14,37,38]$ to give insight into the inhibition action of PSCs on the iron surface. For the purpose of determining the active sites of the inhibitor molecule, three influence factors: natural atomic charge, distribution of frontier orbital, and Fukui indices are considered. Highest occupied molecular orbital energy $\left(E_{\text {HOMO }}\right)$ and lowest unoccupied molecular orbital energy $\left(E_{\mathrm{LUMO}}\right)$ are very popular quantum chemical parameters. These orbitals, also called the frontier orbitals, determine the way the molecule interacts with other species. The HOMO is the orbital that could act as an electron 
Table 3 Total energy $\left(E_{\text {total }}\right)$, hardness $(\eta)$, dipole moment $(\mu)$ and inhibition efficiency (IE) at the inhibitor concentration of $0.1 \mathrm{~m}$ M for PSC molecules 1-5 calculated using DFT at the B3LYP/6-311++G** level of Theory basis set

\begin{tabular}{|c|c|c|c|c|c|c|c|c|}
\hline \multirow[t]{2}{*}{ Molecule } & \multirow{2}{*}{$\begin{array}{l}E_{\text {HOMо }} \\
(\mathrm{eV})\end{array}$} & \multirow{2}{*}{$\begin{array}{l}E_{\text {LUMO }} \\
(\mathrm{eV})\end{array}$} & \multirow{2}{*}{$\begin{array}{l}\Delta E_{\mathrm{gap}}=\left[E_{\mathrm{LUMO}}-E_{\mathrm{HOMO}}\right. \\
(\mathrm{eV})]\end{array}$} & \multirow{2}{*}{$\begin{array}{l}\text { Hardness } \eta \\
(\mathrm{eV})\end{array}$} & \multirow[t]{2}{*}{$E_{\text {total }}$ (a.u.) } & \multirow{2}{*}{$\begin{array}{l}\text { Dipole moment } \mu \\
\text { (Debye) }\end{array}$} & \multicolumn{2}{|c|}{$(\% \mathrm{IE})^{\mathrm{a}}$} \\
\hline & & & & & & & $\mathrm{HNO}_{3}$ & $\mathrm{NaOH}$ \\
\hline PSC_1 & -5.912 & -2.533 & 3.379 & 2.041 & -1165.9688 & 8.641 & 78.4 & 58.3 \\
\hline PSC_2 & -6.148 & -2.062 & 4.086 & 2.510 & -1012.2904 & 7.677 & 76.1 & 55.3 \\
\hline PSC_3 & -6.305 & -2.007 & 4.298 & 1.886 & -795.82109 & 6.790 & 75.2 & 54.1 \\
\hline PSC_4 & -6.457 & -1.831 & 4.626 & 2.346 & -642.12133 & 3.444 & 74.1 & 52.7 \\
\hline PSC_5 & -6.755 & -1.118 & 5.637 & 2.224 & -642.13614 & 1.909 & 73.1 & 48.2 \\
\hline
\end{tabular}

${ }^{\text {a }}$ Measured by weight loss method

donor, since it is the outermost (highest energy) orbital containing electrons. The LUMO is the orbital that could act as the electron acceptor, since it is the innermost (lowest energy) orbital that has room to accept electrons. According to the frontier molecular orbital theory, the formation of a transition state is due to an interaction between the frontier orbitals (HOMO and LUMO) of reactants [39]. The energy of the HOMO is directly related to the ionization potential and the energy of the LUMO is directly related to the electron affinity. The HOMOLUMO gap, i.e., the difference in energy between the HOMO and LUMO is an important stability index. A large HOMO-LUMO gap implies high stability for the molecule in chemical reactions [40]. The concept of "activation hardness" has been also defined on the basis of the HOMO-LUMO energy gap. The qualitative definition of hardness is closely related to the polarizability, since a decrease of the energy gap usually leads to easier polarization of the molecule [41]. Table 3 presents the correlation between the calculated energy levels HOMO, LUMO and the measured inhibition efficiencies IE (\%) of PSCs at $303 \mathrm{~K}$. According to Emregül [4], when length of aminic nitrogen-containing carbon bone chain increased, the corrosion inhibition efficiency increased significantly. The quantum chemistry calculation in this study revealed that as the length increases, the HOMO energy level boosted significantly while the energy gap dropped sharply. The linear correlation between MO energy level and the corrosion inhibition efficiency of the PSCs (Figs. 3, 4, 5) proved that the higher the HOMO energy of the inhibitor, the greater the trend of offering electrons to unoccupied $d$ orbital of the metal, and the higher the corrosion inhibition efficiency for iron in $\mathrm{HNO}_{3}$ acid and $\mathrm{NaOH}$ solutions; in addition, the lower the LUMO energy, the easier the acceptance of electrons from metal surface, as the HOMOLUMO energy gap decreased and the efficiency of inhibitor improved. The relationship between corrosion IE (\%) and HOMO energy levels is plotted in Fig. 3. As

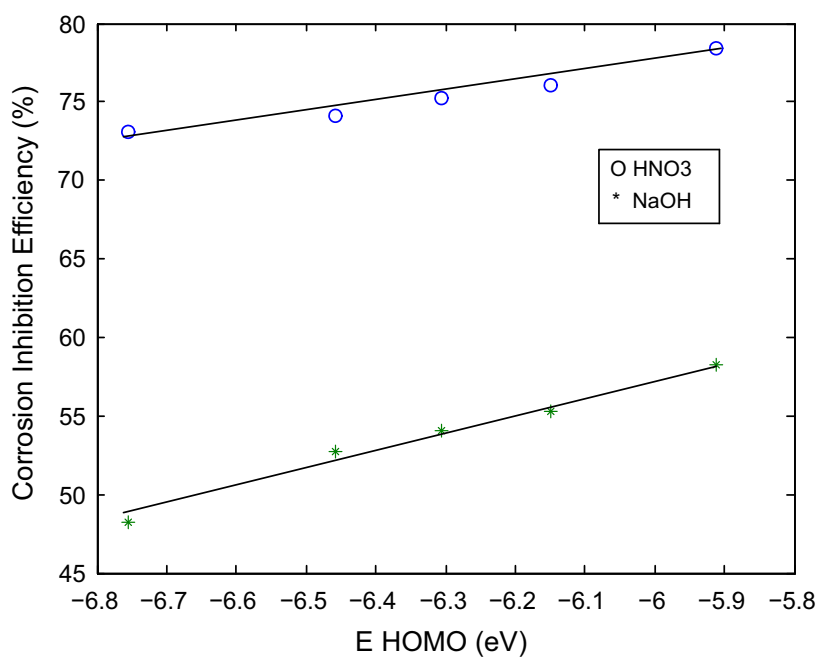

Fig. 3 Correlation of HOMO energy with percent inhibition efficiency (IE \%) of PSCs

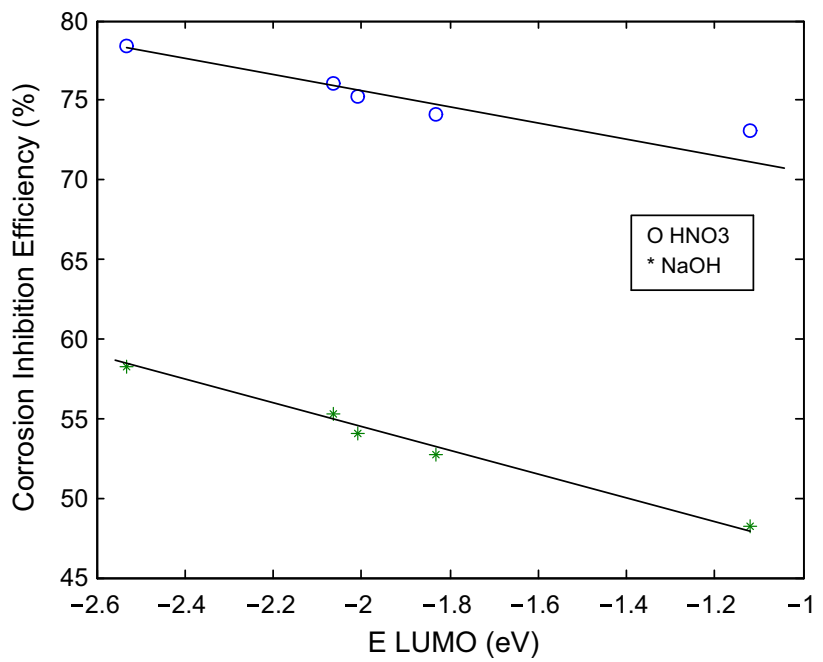

Fig. 4 Correlation of LUMO energy with percent inhibition efficiency (IE \%) of (PSCs) 
clearly seen in the figure, the inhibition efficiency in-

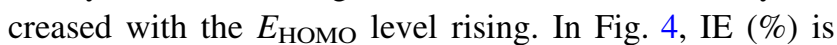
plotted against the LUMO energy, showing that the inhibition efficiency reduced with the $E_{\text {LUMO }}$ level increase. The relationship between the inhibition efficiency and the energy gap $\left(E_{\mathrm{LUMO}}-E_{\mathrm{HOMO}}\right)$ is negative as shown in Fig. 5 . The total energy $\left(E_{\text {total }}\right)$ calculated by quantum chemical methods is also a beneficial parameter. The total energy of a system is presented in Fig. 6, and is composed of the internal, potential, and kinetic energy. Hohenberg and Kohn [42] proved that the total energy of a system including that of the many body effects of electrons (exchange and correlation) in the presence of static external potential (for example, the atomic nuclei) is a unique

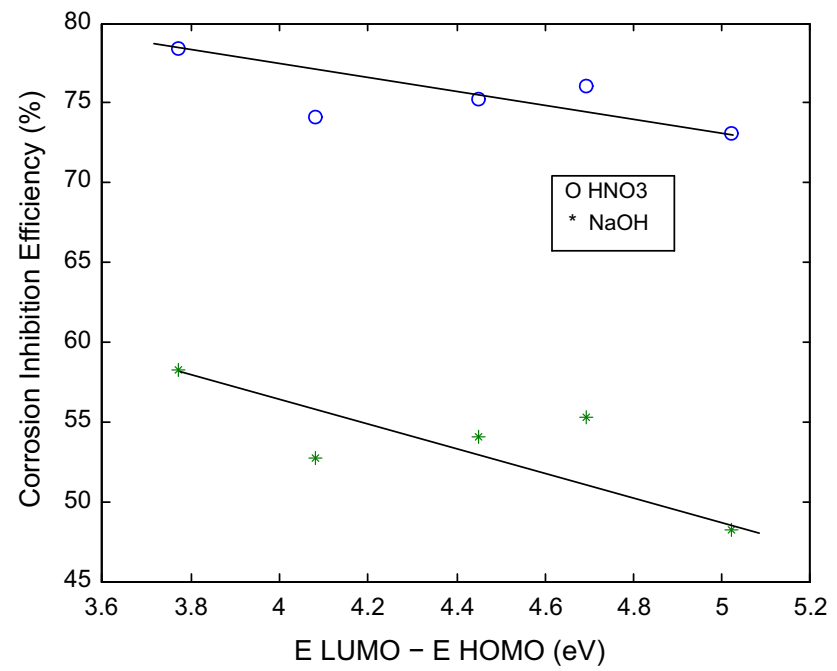

Fig. 5 Correlation of LUMO-HOMO energy gaps with percent inhibition efficiency (IE \%) of PSCs

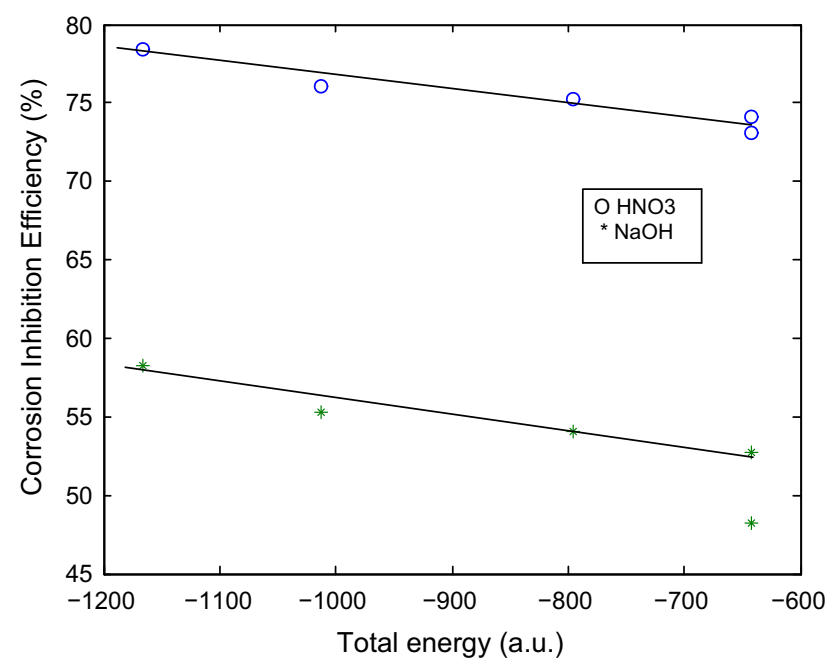

Fig. 6 Correlation of total energy with percent inhibition efficiency (IE \%) of PSCs function of the charge density. The minimum value of the total energy functional is the ground state energy of the system. The electronic charge density which yields this minimum is then the exact single particle ground state energy. The most widely used quantity to describe the polarity is the dipole moment $(\mu)$ of the molecule. Dipole moment $(\mu)$ is the measure of polarity of a polar covalent bond. It is defined as the product of charge on the atoms and the distance between the two bonded atoms. The total dipole moment, however, reflects only the global polarity of a molecule. For a complete molecule, the total molecular dipole moment may be approximated as the vector sum of individual bond dipole moments (Fig. 7). For the purpose of determining the active sites of the inhibitor molecule, three influence factors: natural atomic charge, distribution of frontier orbital, and Fukui indices are considered. According to classical chemical theory, all chemical interactions are by either electrostatic or orbital. Electrical charges in the molecule were obviously the driving force of electrostatic interactions; it has been proven that local electron densities or charges are important in many chemical reactions and physico-chemical properties of compounds [39, 52]. Figures 8,10 and 11 show the optimized geometry, the HOMO density distribution, the LUMO density distribution and the Mullikan charge population analysis plots for PSCs molecules obtained with DFT at the B3LYP/6$311++\mathrm{G}^{* *}$ level of theory.

The reactive ability of the inhibitor is considered to be closely related to their frontier molecular orbitals, the HOMO and LUMO. The frontier molecule orbital density distributions of five PSCs are presented in Figs. 8 and 9. As seen from the figures, the populations the HOMO focused around the carbon chain containing aminic nitrogen. But

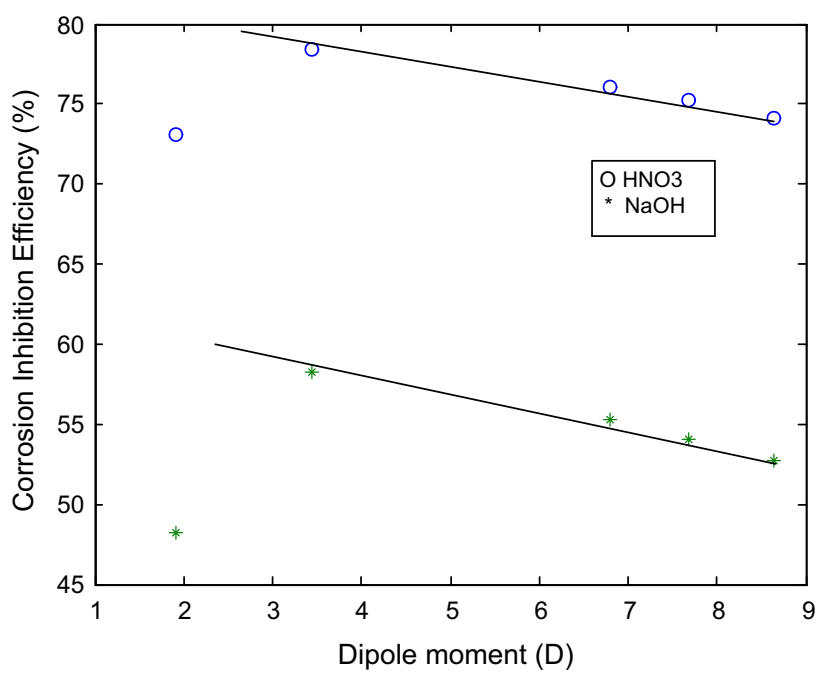

Fig. 7 Correlation of dipole moment $(\mu)$ with percent inhibition efficiency (IE \%) of PSCs 


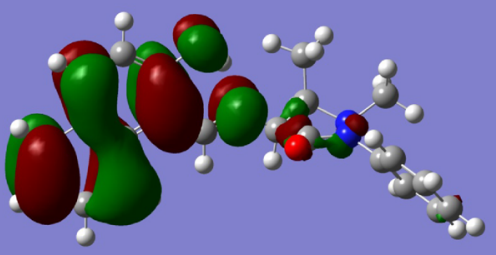

PSC_1

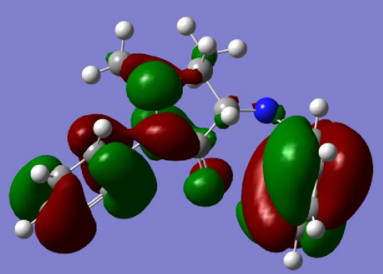

PSC_2

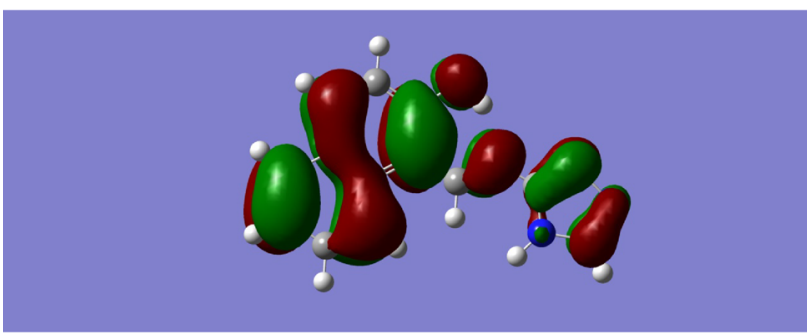

PSC_3

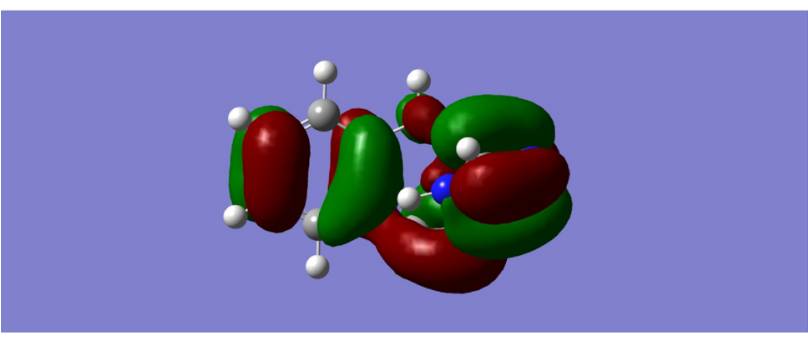

PSC_4

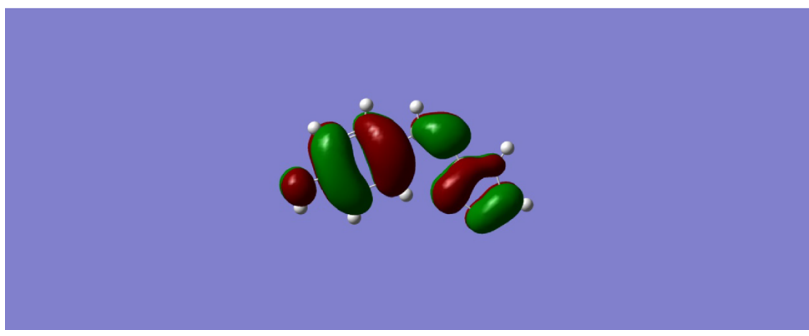

PSC_5

Fig. 8 The highest occupied molecular orbital (HOMO) density of (PSCs) using DFT at the B3LYP/6-311++G** level

the LUMO densities were mainly around the benzene cyclic. Higher HOMO energy $\left(E_{\mathrm{HOMO}}\right)$ of the molecule means a higher electron-donating ability to appropriate

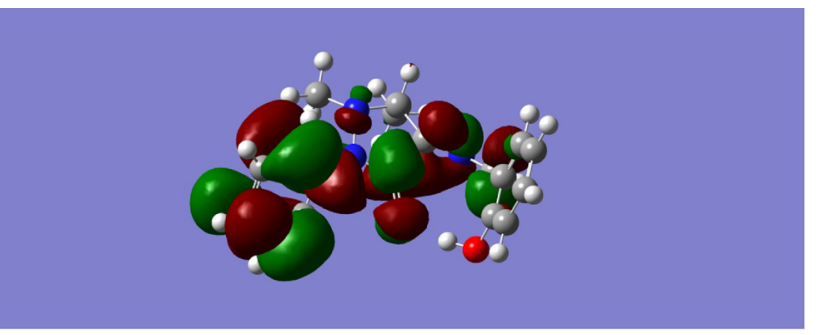

PSC_1

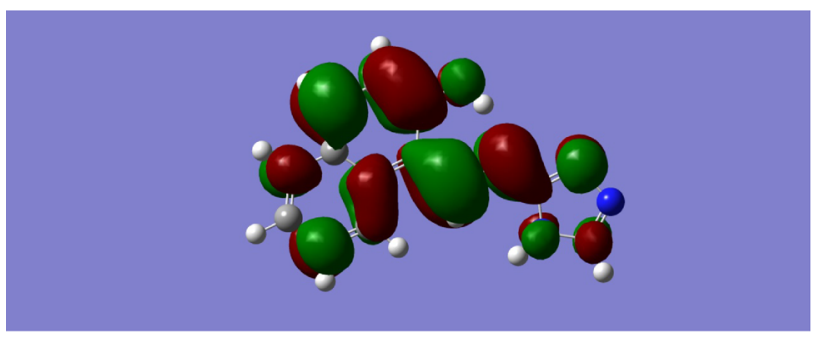

PSC_2

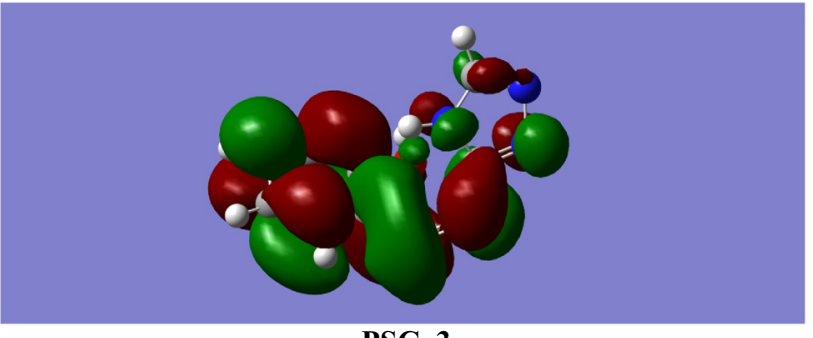

PSC_3

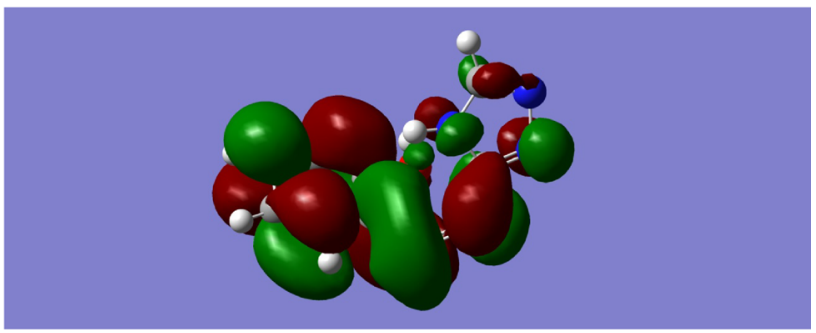

PSC_4

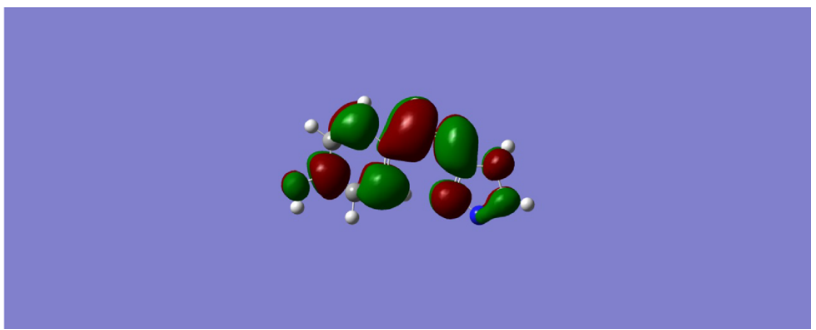

PSC_5

Fig. 9 The lowest unoccupied molecular orbital (LUMO) density of (PSCs) using DFT at the B3LYP/6-311++G** level

acceptor molecules with low-energy empty molecular orbital and thus explains the adsorption on metallic surfaces by way of delocalized pairs of $\pi$-electrons. $E_{\mathrm{LUMO}}$, the 
energy of the lowest unoccupied molecular orbital, signifies the electron receiving tendency of a molecule. The Mulliken charge populations of the five PSCs are also presented in Fig. 10. It can be seen that the area of carbon bone chain containing aminic nitrogen, hydroxyl, and methyl charged a large electron density and might form adsorption active centers. Accordingly, the difference between $E_{\mathrm{LUMO}}$ and $E_{\mathrm{HOMO}}$ energy levels $\left(\Delta E=E_{\mathrm{LUMO}}-E_{\mathrm{HOMO}}\right)$ and the dipole moment $(\mu)$ was also determined. The global hardness $(\eta)$ is approximated as $\Delta E / 2$, and can be defined under the principle of chemical hardness and softness [43]. These parameters also provide information about the reactive behavior of molecules and are presented in Table 3. From Figs. 8 and 9, it could be seen that PSCs have similar HOMO and LUMO distributions, which were all located on the entire PSCs moiety. This is due to the presence of nitrogen and oxygen atoms together with several $\pi$-electrons on the entire molecule. Thus, unoccupied $d$ orbital of Fe atom can accept electrons from inhibitor molecule to form coordinate bond. Also the inhibitor molecule can accept electrons from Fe atom with its anti-bonding orbital's to form back-donating bond. Figure 11 shows B3LYP/6-311G** selected bond length for the optimized geometry of the studied compounds calculated for PSCs. It has been reported that the more negative the atomic charges of the adsorbed centre, the more easily the atom donates its electron to the unoccupied orbital of the metal [43]. It is clear from Fig. 11 that nitrogen and oxygen as well as some carbons atoms carry negative charge centers which could offer electrons to the iron surface to form a coordinate bond. This shows that the two $\mathrm{N}$ and $\mathrm{O}$ atoms are the probable reactive sites for the adsorption of iron. Higher values of $E_{\mathrm{HOMO}}$ are likely to indicate a tendency of the molecule to donate electrons to appropriate acceptor molecules with low energy or empty electron orbital. It is evident from Table 3 that PSCs has the highest $E_{\mathrm{HOMO}}$ and a lower $E_{\mathrm{HOMO}}$ in the neutral form. This means that the electron-donating ability of PSCs is weaker in the neutral form. This confirms the experimental results that interaction between PSCs and iron is electrostatic in nature (physisorption). The energy of the LUMO is directly related to the electron affinity and characterizes the susceptibility of the molecule towards attack by neucleophiles. The lower the values of $E_{\mathrm{LUMO}}$, the stronger the electron accepting abilities of molecules. It is clear that the protonated form of PSCs exhibits the lowest $E_{\mathrm{HOMO}}$, thus the protonated form is the most likely form for the interaction of iron with PSCs molecule. Low values of the energy gap $(\Delta E)$ will provide good inhibition efficiencies, because the excitation energy to remove an electron from the last occupied orbital will be low [44]. A molecule with a low-energy gap is more polarizable and is generally associated with a high chemical reactivity and low kinetic

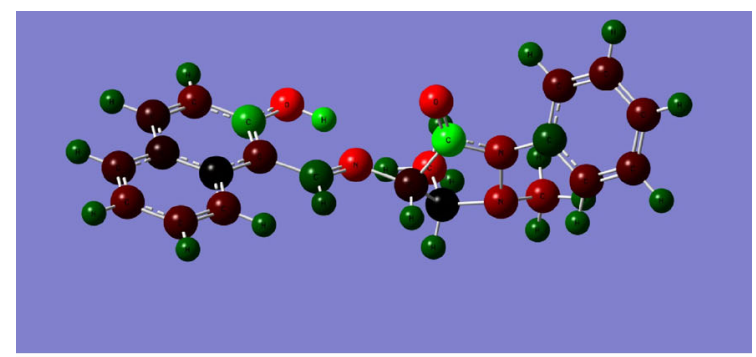

PSC_1

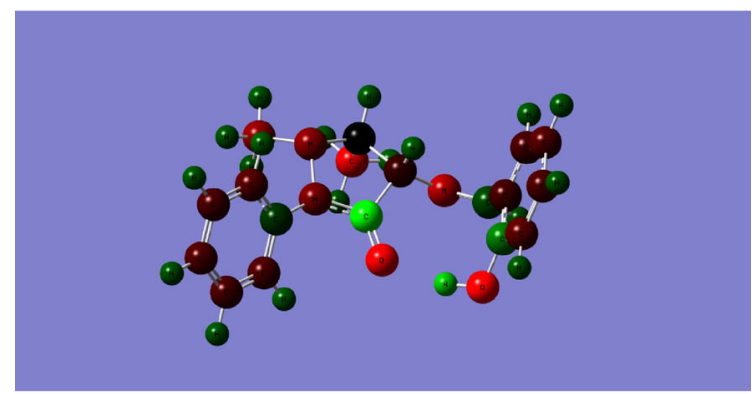

PSC_2

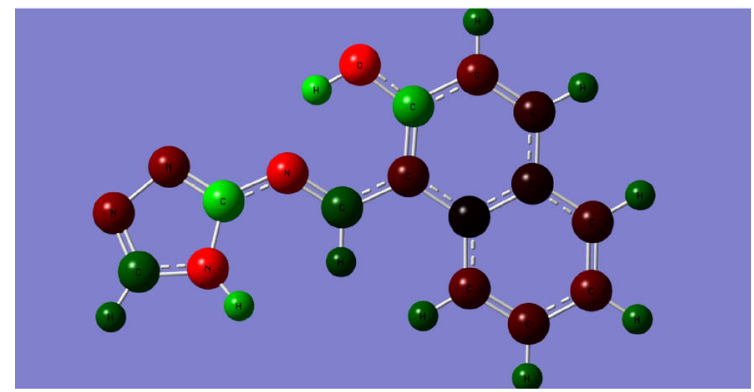

PSC_3

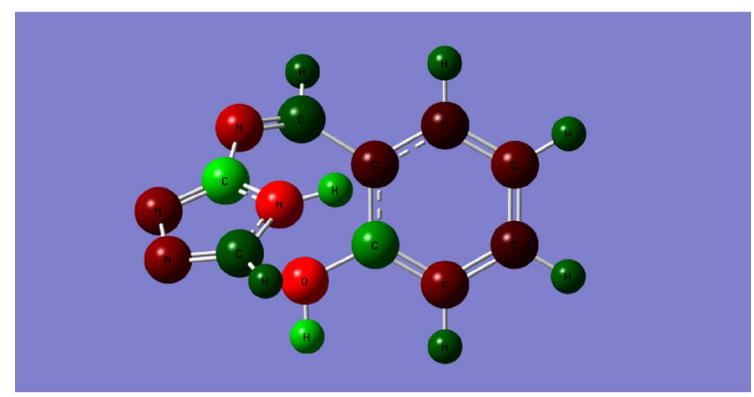

PSC_4

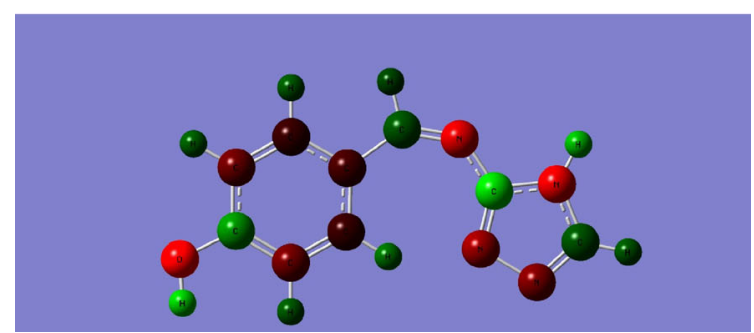

PSC_5

Fig. 10 Optimized structure of Polydentate Schiff base compounds (PSCs) 
Fig. 11 Mulliken orbital charges populations analysis of (PSC) using DFT at the B3LYP/ 6-311G** basis set level

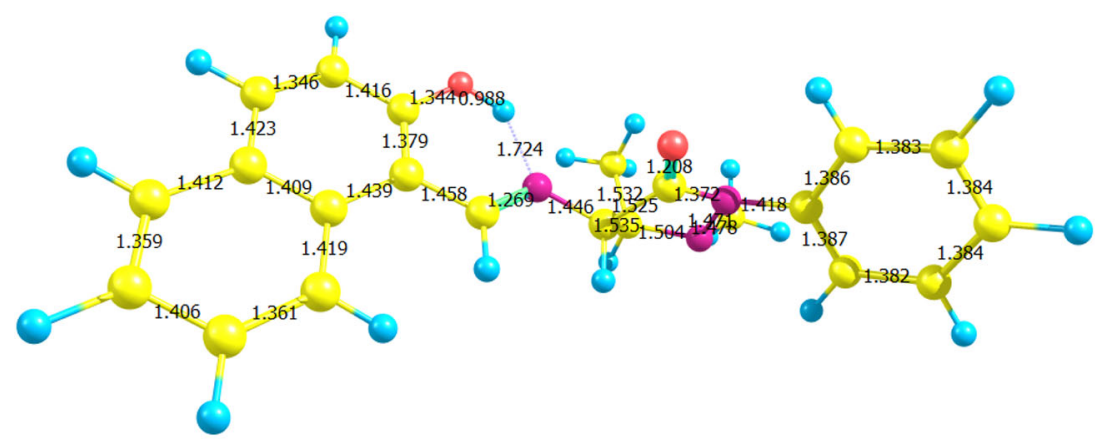

PSC_1

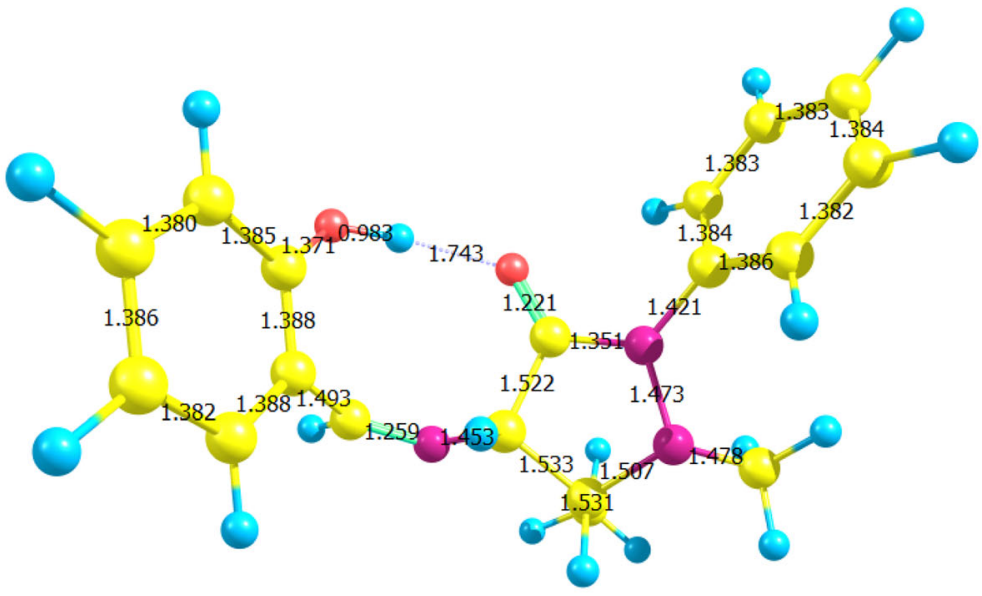

PSC 2

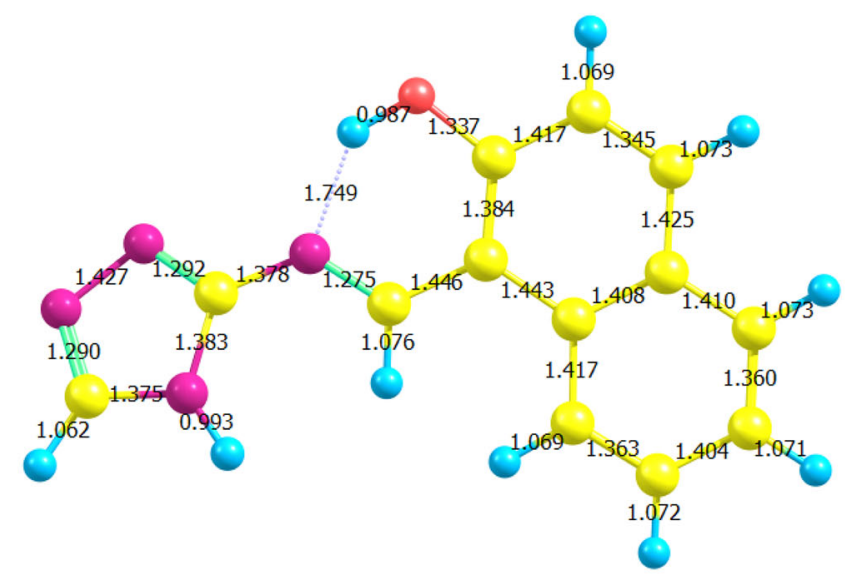

PSC_3

stability, and is termed soft molecule [45]. According to Wang et al. [46], adsorption of inhibitor onto a metallic surface occurs at the part of the molecule which has the greatest softness and lowest hardness. The results show that
PSCs in the protonated form have the lowest energy gap and lowest hardness; this agrees with the experimental results that PSCs could have better inhibitive performance on iron surface, i.e., through electrostatic interaction 
Fig. 11 continued

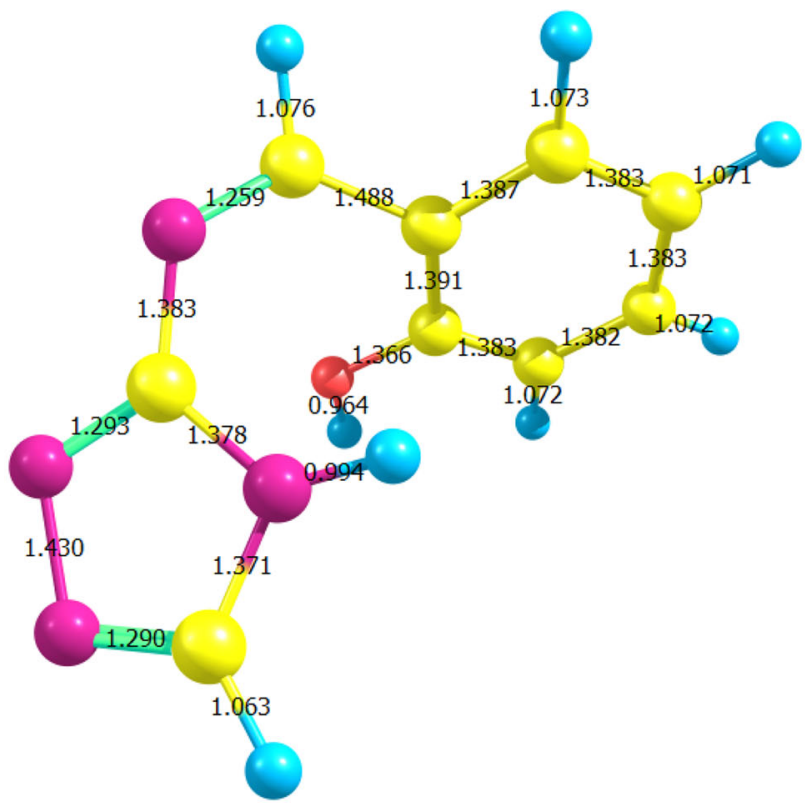

PSC_4

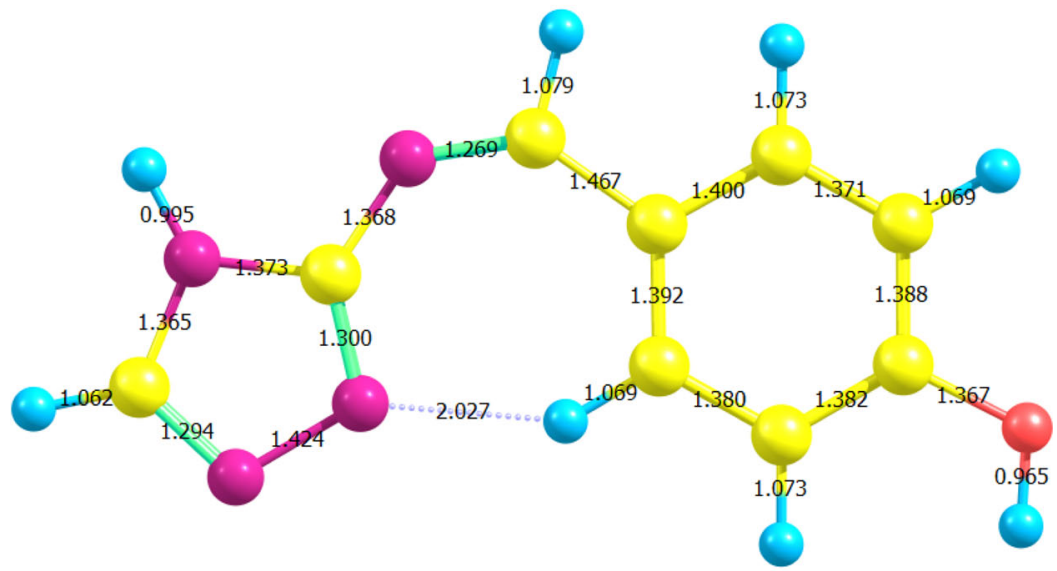

PSC 5

between the cation form of PSCs and the vacant $d$-orbital of iron (physisorption). PSCs had the highest inhibition efficiency because it had the highest HOMO energy values, and it had the greatest ability of offering electrons. This also agrees well with the value of $\Delta G^{\circ}$ ads obtained experimentally (Table 4). The dipole moment $(\mu)$ is another important electronic parameter that results from non-uniform distribution of charges on the various atoms in a molecule. It is mainly used to study the intermolecular interactions involving the Van der Waals type dipoledipole forces, etc., because the larger the dipole moment as shown in Table 3, the stronger will be the intermolecular attraction [45]. The dipole moment of PSCs is highest in the protonated form $[\mu=8.641$ Debye $\left.\left(28.818 \times 10^{-30} \mathrm{Cm}\right)\right]$, which is higher than that of $\mathrm{H}_{2} \mathrm{O}$ $\left(\mu=6.23 \times 10^{-30} \mathrm{Cm}\right)$. The high value of dipole moment probably increases the adsorption between chemical compound and metal surface [47]. Accordingly, the adsorption of PSC molecules can be regarded as a quasi-substitution process between the PSC compound and water molecules at the electrode surface. Frontier orbital energy level indicates the tendency of bonding to the metal surface. Further study on the formation of chelating centers in an inhibitor requires the information of spatial distribution of electronic density of the compound molecules [48]. The structure of the molecules can affect the adsorption by influencing the electron density at the functional group. Generally, electrophiles attack the molecules at negative 
Table 4 Binding constant $\left(K_{\mathrm{b}}\right)$, active sites $(1 / y)$, lateral interaction $(f)$, equilibrium constant $\left(K_{\text {ads }}\right)$ and standard free energy of adsorption of iron in $2.0 \mathrm{M} \mathrm{HNO}_{3}$ and $2.0 \mathrm{M} \mathrm{NaOH}$ for PSC molecules 1-5 at $303 \mathrm{~K}$ $(r=0.94)$

\begin{tabular}{|c|c|c|c|c|c|c|c|}
\hline \multirow[t]{2}{*}{ Inhibitor } & \multirow[t]{2}{*}{ Medium } & \multicolumn{3}{|c|}{ Kinetic model } & \multicolumn{3}{|c|}{ Temkin adsorption isotherm } \\
\hline & & $1 / y$ & $K_{\mathrm{b}}$ & $-\Delta \mathrm{G}^{\circ}(\mathrm{kJ} / \mathrm{mol})$ & $-f$ & $K_{\text {ads }}$ & $-\Delta G^{\circ}(\mathrm{kJ} / \mathrm{mol})$ \\
\hline \multirow[t]{2}{*}{ PSC_1 } & $\mathrm{HNO}_{3}$ & 10.44 & $1.8 \times 10^{8}$ & 37.75 & 23.46 & 36,307 & 16.33 \\
\hline & $\mathrm{NaOH}$ & 4.80 & $3.3 \times 10^{4}$ & 16.01 & 31.55 & 13,803 & 13.89 \\
\hline \multirow[t]{2}{*}{ PSC_2 } & $\mathrm{HNO}_{3}$ & 10.00 & $1.2 \times 10^{8}$ & 36.81 & 24.16 & 31,622 & 15.98 \\
\hline & $\mathrm{NaOH}$ & 4.54 & $2.2 \times 10^{4}$ & 15.11 & 33.30 & 12,302 & 13.60 \\
\hline \multirow[t]{2}{*}{ PSC_3 } & $\mathrm{HNO}_{3}$ & 9.32 & $7.3 \times 10^{7}$ & 35.50 & 24.44 & 30,408 & 15.88 \\
\hline & $\mathrm{NaOH}$ & 4.16 & $1.8 \times 10^{4}$ & 14.53 & 33.97 & 11,800 & 13.50 \\
\hline \multirow[t]{2}{*}{ PSC_4 } & $\mathrm{HNO}_{3}$ & 7.98 & $5.3 \times 10^{7}$ & 34.67 & 24.82 & 28,575 & 15.75 \\
\hline & $\mathrm{NaOH}$ & 3.85 & $9.7 \times 10^{3}$ & 13.01 & 34.47 & 9332 & 12.91 \\
\hline \multirow[t]{2}{*}{ PSC_5 } & $\mathrm{HNO}_{3}$ & 6.73 & $4.2 \times 10^{7}$ & 34.18 & 25.15 & 27,227 & 15.60 \\
\hline & $\mathrm{NaOH}$ & 3.72 & $8.6 \times 10^{3}$ & 12.71 & 37.86 & 8917 & 12.30 \\
\hline
\end{tabular}

charged sites. As seen from Fig. 10, the electron density focused on $\mathrm{N}$ atoms, $\mathrm{O}$ atoms, and $\mathrm{C}$ atoms in methyl. The regions of highest electron density are generally the sites to which electrophiles attacked. So, N, O, and C atoms were the active center, which had the strongest ability of bonding to the metal surface. On the other side, HOMO (Fig. 8) was mainly distributed in the areas containing aminic nitrogen. Thus, the areas containing $\mathrm{N}$ atoms were probably the primary sites of the bonding. As shown in Table 3, the values of HOMO energy increases with increasing length of carbon bone chain containing aminic nitrogen. Similar situation can be also seen in Figs. 10 and 11, the configuration changes led to the increase in electron density, and inhibition efficiency was enhanced by increase in HOMO energy and electron density. It is concluded the region of active centers transforming electrons from $\mathrm{N}$ atoms to iron surface. The electron configuration of iron is [Ar] $4 s^{2} 3 d^{6}$; the $3 d$ orbitals are not fully filled with electrons. $\mathrm{N}$ heteroatom has lonely electron pairs that are important for bonding unfilled $3 \mathrm{~d}$ orbitals of the iron atom and determining the adsorption of the molecules on the metal surface. PSC_1 had the highest inhibition efficiency among the PSCs, which was resulted from the geometry change that led to HOMO energy increase and electron density distribution in the molecule. Based on the discussion above, it can be concluded that the PSCs molecules have many active centers of negative charge. In addition, the areas containing $\mathrm{N}$ and $\mathrm{O}$ atoms are the most possible sites of bonding metal surface by donating electrons to the metal iron.

\section{Kinetics of iron corrosion in $\mathrm{HNO}_{3}$ with and without PSCs}

The kinetics of iron corrosion with and without different concentrations of PSCs in $2.0 \mathrm{M} \mathrm{HNO}_{3}$ was studied at $303 \mathrm{~K}$ by fitting the corrosion data into different rate laws.
Correlation coefficients $R^{2}$ were used to determine the best rate law for the corrosion process. The rate laws considered were [49]:

Zero-order: $W_{\mathrm{t}}=k t$

First-order: $\ln W_{\mathrm{t}}=-k t+\ln W_{\mathrm{o}}$

Second-order: $1 / W_{\mathrm{t}}=k t+1 / W_{\mathrm{o}}$

where $W_{\mathrm{o}}$ is the initial weight of iron, $W_{\mathrm{t}}$ is the weight loss of iron at time $t$ and $k$ is the rate constant. By far the best result was obtained for first-order kinetics. The plot of $1 n$ $W \mathrm{t}$ against $t$ which was linear (Fig. 12) with good correlation coefficients $\left(R^{2}>0.9\right)$ confirms first-order kinetics for the corrosion of iron in $2.0 \mathrm{M} \mathrm{HNO}_{3}$ in the absence and presence of PSC_1. The corrosion rate of iron in nitric acid medium is under anodic control [35] which is:

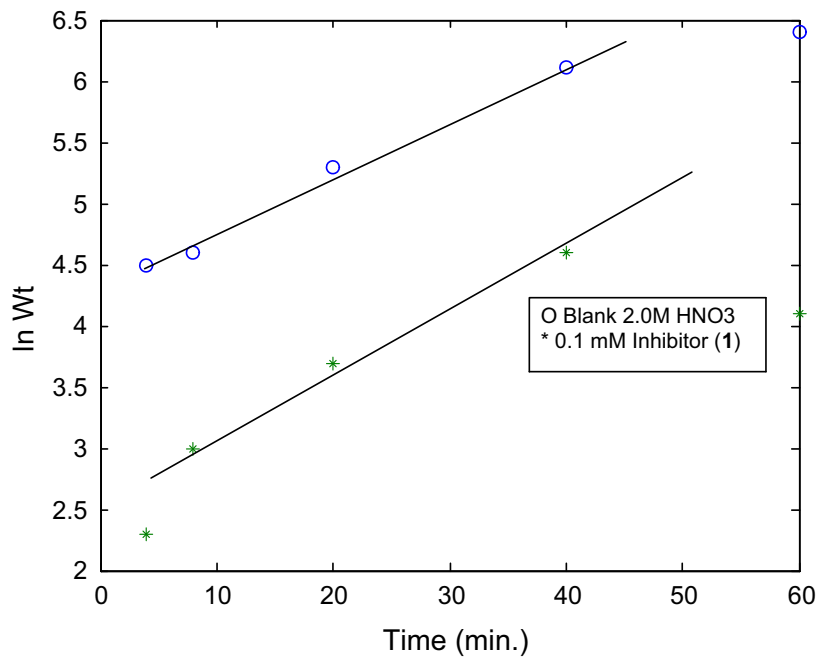

Fig. 12 The plot of $\ln \mathrm{Wt}$ against $t$ for iron corrosion in $2.0 \mathrm{M} \mathrm{HNO}_{3}$ with and without inhibitor (PSC_1) 
$\mathrm{Fe}+\mathrm{OH}^{-}(\mathrm{rds}) \rightleftarrows \mathrm{FeOH}_{\mathrm{ads}}+\mathrm{H}^{+}+\mathrm{e}$

$\mathrm{FeOH}_{\mathrm{ads}} \rightarrow \mathrm{FeOH}^{+}+\mathrm{e}$

$\mathrm{FeOH}^{+}+\mathrm{H}^{+} \rightleftarrows \mathrm{Fe}^{2+}+\mathrm{H}_{2} \mathrm{O}$

where 'rds' stands for rate-determining step.

Figure 12 reflects the reaction order with respect to iron. This result suggests that the presence of PSC does not influence the anodic reaction order. The linearity of the curves in the absence and presence of PSC implies that its presence does not change the kinetics of the corrosion reaction though the rate might be considerably reduced. Similar report has been documented elsewhere [50]. The half-life $\left(t_{1 / 2}\right)$ value was calculated [51] using the following relationship:

$t_{1 / 2}=0.693 / k$

The values of rate constant and half-life periods obtained are calculated and summarized. The value of the rate constant $(k)$ was found to be higher in the case of inhibited iron samples (0.087) than uninhibited samples $(0.049)$ whereas half-life $\left(t_{1 / 2}\right)$ was found to be lower in the presence of inhibitor $(8.0 \mathrm{~min})$ than in its absence $(14.0 \mathrm{~min})$. This implies that the corrosion rate is higher in the absence of inhibitor than with inhibited mild iron samples. Similar results were reported on the kinetics of some organic compounds $[52,53]$. Another indication of the rate of a firstorder reaction is the time constant, $\tau$, [53]. The time required for the concentration of the reactant to fall to $1 / 2 e$ of its initial value. The calculated values of the time constants are also presented and correlated. The results show that the time constants were lower $(11.58 \mathrm{~min})$ in the presence of PSC_1 than in its absence (20.26 min). This confirms that the presence of the (PSC) inhibitor decreases the dissolution of iron.

\section{Adsorption isotherm and thermodynamic consideration}

The adsorption isotherm can be determined if the inhibitor effect is due mainly to the adsorption on the metal surface (i.e., to its blocking). The type of the adsorption isotherm can provide additional information about the properties of the tested (PSCs). Several adsorption isotherms were assessed, and the Temkin adsorption isotherm was found to provide the best description of the adsorption behavior of the investigated inhibitors. The Temkin isotherm is given by the equation [54]:

$\exp (f \cdot \theta)=K_{\mathrm{ads}} \cdot C$
The plots of logarithmic concentration of PSC inhibitors $(\log C)$ vs. the surface coverage $(\theta)$ of inhibitors gave straight lines. Consequently, the adsorption of Schiff bases and Schiff base-metal complexes on the surface of iron was found to be governed by the Temkin adsorption isotherm [55] namely:

$\theta=a+\ln b C$

where $C$ is the concentration of the additive in the bulk of the solution, $(\theta)$ is the degree of coverage of the iron surface by the adsorbed molecules; $a$ and $b$ are constants. $K_{\text {ads }}$ are the equilibrium constant for the adsorption process and it is calculated and tabulated in Table 4 . The value of $K_{\text {ads }}$ was calculated as $36307 \mathrm{M}^{-1}$ for PSC_1 in $\mathrm{HNO}_{3}$ acid at $303 \mathrm{~K}$. The relatively high value of adsorption equilibrium constant reflects the high adsorption ability of PSCs on iron surface [56]. The standard free energy of adsorption $\left(\Delta G_{\text {ads }}^{\circ}\right)$ is related to adsorption constant $\left(\mathrm{K}_{\mathrm{ads}}\right)$ with the following equation [57]:

$\Delta G_{\mathrm{ads}}^{\circ}=-R T\left(\ln 55.5 K_{\mathrm{ads}}\right)$

where $R$ is the universal gas constant $\left(\mathrm{kJ} \mathrm{mol}^{-1} \mathrm{~K}^{-1}\right)$ and $\mathrm{T}$ is the absolute temperature $(\mathrm{K})$. The value of 55.5 is the molar concentration of water in solution expressed in mol $\mathrm{L}^{-1}$. Using the Eq. (17), the calculated values of $\Delta G^{\circ}$ ads and $K_{\text {ads }}$ of the synthesized PSC inhibitors are listed in Table 4. The negative values of $\Delta G^{\circ}$ ads indicate the spontaneous adsorption of these molecules on the metal surface [58] and strong interactions between inhibitor molecules and the metal surface [59]. The $\Delta G^{\circ}$ ads was calculated as $-16.33 \mathrm{~kJ} \mathrm{~mol}^{-1}$ for the same compound PSC_1 in $\mathrm{HNO}_{3}$ acid. The value of $\Delta G_{\text {ads }}^{\circ}$ indicates the strong interaction between inhibitor molecules and the Fe surface. It is well known that values of $\Delta G_{\text {ads }}^{\circ}$ of the order of 12$16 \mathrm{~kJ} \mathrm{~mol}^{-1}$ or lower in acidic and alkaline solutions (Table 4) indicate a physisorption mechanism. In addition to electrostatic interaction, there may be some other interactions $[60,61]$. The high $K_{\text {ads }}$ and $\Delta G^{\circ}$ ads values may be attributed to higher adsorption of the inhibitor molecules at the metal-solution interface [62]. In physisorption process, it is assumed that acid anions such as $\mathrm{NO}_{3}{ }^{-}$ions are specifically adsorbed on the metal surface, donating an excess negative charge to the metal surface. In this way, potential of zero charge becomes less negative which promotes the adsorption of inhibitors in cationic form [63]; those of order of $40 \mathrm{~kJ} \mathrm{~mol}^{-1}$ or higher involve charge sharing or transfer from the inhibitor molecules to the metal surface to form a coordinate type of bond (chemisorptions) [64]. Straight lines of $C I n h / \theta$ versus $C I n h$ 


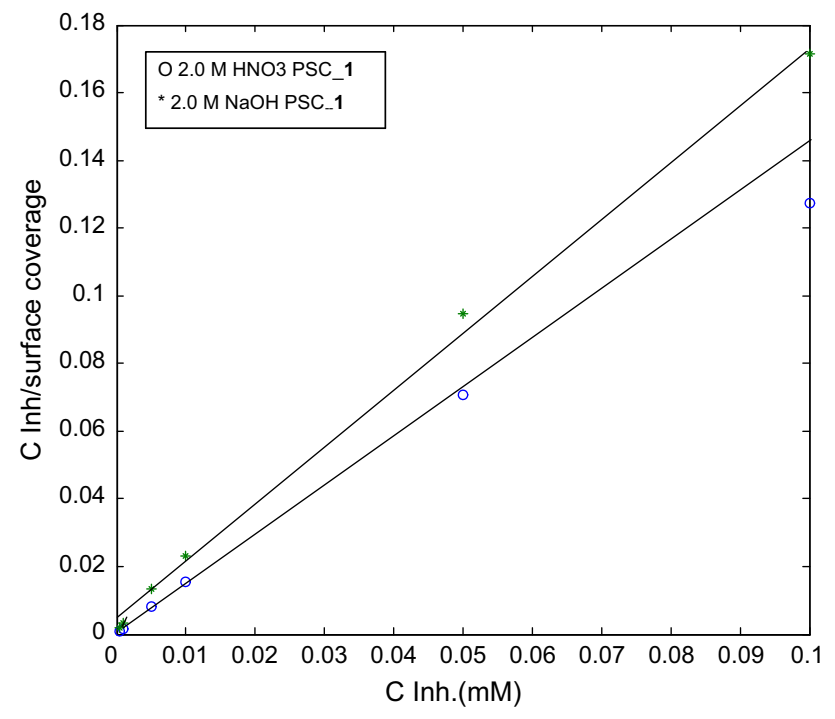

Fig. 13 Relation between $\mathrm{C}$ Inh.and $\mathrm{C}$ Inh/surface coverage of (PSC_1) for iron in $\mathrm{HNO}_{3}$ and $\mathrm{NaOH}$ at $303 \mathrm{~K}$

plots indicate that the adsorption of the inhibitor molecules on the metal surface obeyed Temkin adsorption model (Fig. 13). This isotherm can be represented as:

$\operatorname{CInh} / \theta=1 / \operatorname{Kads}+\operatorname{CInh}$

The strong correlation coefficients of the fitted curves are around unity $(r=0.94)$. This reveals that the inhibition tendency of the inhibitors is due to the adsorption of these synthesized molecules on the metal surface [65] (Table 4). The slopes of the $C I n h / \theta$ versus $C I n h$ plots are close to $\equiv 1.38$ in case of nitric acid, whereas $\equiv 2.53$ in the case of $\mathrm{NaOH}$ solution which indicates the ideal simulating and expected from Temkin adsorption isotherm [65]. $K_{\text {ads }}$ values were calculated from the intercepts of the straight lines on the $C \operatorname{Inh} / \theta$ axis [66]. Generally, the relatively high values of the adsorption equilibrium constant $\left(K_{\text {ads }}\right)$ as given in Table 4 reflect the high adsorption ability [58, 59] of the PSC molecules on the iron surface. To evaluate the kinetic parameters and correlate them to their corrosion inhibition mechanism, it is now of value to analyze the kinetic data obtained in the presence of the studied PSC inhibitors from the stand point of the generalized mechanistic scheme proposed by El-Awady et al. [67, 68]. The correlation between kinetic-thermodynamic model and adsorption data for iron corrosion in $2.0 \mathrm{M} \mathrm{HNO}_{3}$ and $2.0 \mathrm{M} \mathrm{NaOH}$ solutions at $303 \mathrm{~K}$ in presence of PSCs is given in Eq. 20.

$\theta /(1-\theta)=K^{\prime}[I]^{y}$

or $\log (\theta / 1-\theta)=\log K^{\prime}+y \log [I]$

where $y$ is the number of inhibitors molecules $[I]$ occupying one active site, and $\mathrm{K}^{\prime}$ is a constant. The relationship in Eq. (20) gives a satisfactory linear relation. Hence, the suggested model fits the obtained experimental data. The slope of such lines is the number of inhibitor molecules occupying a single active site, $(y)$ and the intercept is the binding constant $\left(\log K^{\prime}\right)$. As mentioned, $1 / y$ gives the number of active sites occupied by a single organic molecule and $\mathrm{K}^{\prime y}$ is the equilibrium constant for the adsorption process. The binding constant $\left(K_{\mathrm{b}}\right)$ corresponding to that obtained from the known adsorption isotherms curve fitting is given by the following equation:

$K_{\mathrm{b}}=\mathrm{K}^{\prime(1 / \mathrm{y})}$

Table 4 comprises the values of $1 / y$ and $K_{b}$ for the studied (PSCs). This table shows the number of active sites occupied by one molecule in the case of PSCs $(1 / y \equiv 4-11)$. Values of $1 / y$ greater than unity imply the formation of multilayer of the inhibitor molecules on the metal surface, whereas values of $1 / y$ less than unity indicate that a given inhibitor molecule will occupy more than one active site [69]. According to the proposed kineticthermodynamic model, the adsorption takes place via the formation of multilayer of the inhibitor molecules on the iron electrode surface. The slope values do not equal unity (gradient slopes $<1$ ) and, hence, the adsorption of these synthesized PSCs on iron surface does not obey a Langmuir adsorption isotherm [70, 71]. Temkin adsorption isotherm (Eq. 16) represents best fit for experimental data obtained from applying PSCs as chemical inhibitors on iron in $2.0 \mathrm{M} \mathrm{HNO}_{3}$ and $2.0 \mathrm{M} \mathrm{NaOH}$ solutions. The values of $K_{\text {ads }}$ (equilibrium constant of the inhibitor adsorption process) and $(f)$ are tabulated in Table 4 . The lateral interaction parameter $(f)$ has negative values; this parameter is a measure of the degree of steepness of the adsorption isotherm. The adsorption equilibrium constant $\left(K_{\text {ads }}\right)$ calculated from Temkin equation acquires lower values than binding constant $\left(K_{\mathrm{b}}\right)$ obtained and calculated from the kinetic-thermodynamic model. The lack of compatibility of the calculated $(K b)$ and experimental $\left(K_{\text {ads }}\right)$ values may be attributed to the fact that Temkin adsorption isotherm is only applicable to cases where one active site per inhibitor molecule is occupied. The lateral interaction parameter was introduced to treat deviations from Langmuir ideal behavior, whereas the kinetic-thermodynamic model uses the size parameter. The values of the lateral interaction parameter $(-f)$ were found to be negative and increase from $\equiv 23$ to 38 . This denotes that an increase in the adsorption energy takes place with the increase in the surface coverage $(\theta)$. Adsorption process is a displacement reaction involving removal of adsorbed water molecules from the electrode metal surface and their substitution by inhibitor molecules. Thus, during adsorption, the adsorption equilibrium forms an important part in the overall free energy changes in the process of adsorption. It 
has been shown [72] that the free energy change $\left(\Delta G^{\circ}{ }_{\text {ads }}\right)$ increases with increase in the solvating energy of adsorbing species, which in turn increases with the size of hydrocarbon portion in the organic molecule and the number of active sites. Hence, the increase of the molecular size leads to decreased solubility, and increased adsorbability. The large negative values of the standard free energy changes of adsorption ( $\Delta G^{\circ}$ ads $)$, obtained for PSCs, indicate that the reaction is proceeding spontaneously and accompanied with a high efficient adsorption. However, the large difference values of the binding constant $\left(K_{\mathrm{b}}\right)$ from the kinetic model compared with the modified equilibrium constant values $\left(K_{\text {ads }}\right)$ from Temkin equation are incompatible (Table 4), mean better inhibition efficiency of the investigated synthesized PSCs, i.e., stronger electrical interaction between the double layer existing at the phase boundary and the adsorbing molecules. In general, the equilibrium constant of adsorption ( $K_{\text {ads }}$ ) was found to become higher with increasing the inhibition efficiency of the inhibitor studied as given in Table 4.

\section{Mechanism of corrosion inhibition}

Weight loss, thermometric, polarization and inhibition efficiency (IE) for PSC molecules 1-5 calculated with concentration of: $1 \times 10^{-4} \mathrm{M}$ at $303 \mathrm{~K}$ are collected in Table 5. From the experimental and theoretical results obtained, we note that a plausible mechanism of corrosion inhibition of iron in aerated 2.0 $\mathrm{M} \mathrm{HNO}_{3}$ and 2.0 $\mathrm{M} \mathrm{NaOH}$ using (PSCs) may be deduced on the basis of adsorption. The transition of metal/solution interface from a state of active dissolution to the passive state is attributed to the adsorption of the inhibitor molecules and the metal surface, forming a protective film [73]. Thermodynamic parameters showed that the adsorption of PSCs on the iron surface either in acidic and/or alkaline solutions is physical than chemical one. The adsorption of PSC arises from the donor acceptor interactions between free electron pairs of hetero

Table 5 Weight loss, thermometric, polarization and inhibition efficiency (IE) for PSC molecules 1-5 calculated with concentration of $1 \times 10^{-4} \mathrm{M}$ at $303 \mathrm{~K}$

\begin{tabular}{|c|c|c|c|c|c|c|}
\hline \multicolumn{7}{|l|}{ IE $(\%)$} \\
\hline \multirow[t]{2}{*}{ Inhibitor } & \multicolumn{2}{|c|}{ Weight loss } & \multicolumn{2}{|c|}{ Thermometric } & \multicolumn{2}{|c|}{ Polarization } \\
\hline & $\mathrm{HNO}_{3}$ & $\mathrm{NaOH}$ & $\mathrm{HNO}_{3}$ & $\mathrm{NaOH}$ & $\mathrm{HNO}_{3}$ & $\mathrm{NaOH}$ \\
\hline PSC_1 & 78.4 & 58.3 & 75.9 & - & 73.8 & 63.2 \\
\hline PSC_2 & 76.1 & 55.3 & 75.0 & - & 72.0 & 58.1 \\
\hline PSC_3 & 75.2 & 54.1 & 74.1 & - & 71.1 & 62.3 \\
\hline PSC_4 & 74.1 & 52.7 & 73.7 & - & 69.8 & 56.8 \\
\hline PSC_5 & 73.1 & 48.2 & 71.5 & - & 68.6 & 55.3 \\
\hline
\end{tabular}

atoms and $\pi$ electrons of multiple bonds as well as phenyl group and vacant $d$ orbitals of iron [6, 74]. It has been reported that the adsorption of heterocyclic compounds occurs with the aromatic rings sometimes parallel, but mostly normal to the metal surface. The orientation of molecules could be dependent on the $\mathrm{pH}$ and/or electrode potential. However, more work should be completed to confirm the above arguments [75]. In the case of parallel adsorption of inhibitor molecules, the steric factors also must be taken into consideration. The adsorption of organic molecules on the solid surfaces cannot be considered only as purely physical or as purely chemical adsorption phenomenon. In addition to the physical adsorption, inhibitor molecules can also be adsorbed on the iron surface via electrostatic interaction between the charged metal surface and charged inhibitor molecule if it is possible. The calculated standard free energy of adsorption has been found close to $-17 \mathrm{~kJ} \mathrm{~mol}^{-1}$ (Table 4), which can be explained as physical rather than chemical adsorption. If the contribution of electrostatic interactions takes place, the following adsorption process can additionally be discussed. The essential effect of Schiff bases as corrosion inhibitors is due to the $\mathrm{C}=\mathrm{N}$ group in the molecules Schiff bases, $\pi$ electrons on the aromatic rings, mode of interaction with the metal surface and the formation of metallic complexes $[3,76,77]$. The unshared and $\pi$ electrons interact with $d$ orbital of Fe to provide a protective film. Five Schiff bases investigated in the present study have one, two, and/or three benzene rings: one hetero nitrogen-five member ring and $\mathrm{C}=\mathrm{N}$ group. The optimized geometry of Schiff bases (PSC_1-5) is presented in Fig. 11. According to Fig. 11, each molecule of Schiff bases has an $\mathrm{OH}$ group in the ortho position for PSCs (1-4), and in para position for PSC_5, one group $\mathrm{C}=\mathrm{N}$ presence between benzene rings and the hetero nitrogen-five member ring. In addition, $\mathrm{PSC}_{-} \mathbf{1}$ and PSC_ 2 has an excess $\mathrm{O}$ atom in the ortho position and two $\mathrm{CH}_{3}$ groups in $o$ - and $m$-positions at the hetero nitrogenfive member ring linked to carbon of $\mathrm{C}=\mathrm{N}$ group. The inhibition efficiency IE (\%) values of Schiff bases (1-5) at a common concentration of $0.1 \mathrm{mM}$ (Table 5) follow the order: PSC_1 $>$ PSC_2 $>$ PSC_3 $>$ PSC_4 $>$ PSC_5. The quantum results were used to explain different inhibition effectiveness of the Schiff base molecules. From optimized geometry of Schiff bases given in Fig. 11, it can be observed that all (PSCs) have approximate planar structure. Thus, the adsorption of studied Schiff bases on iron surface would take place through $\mathrm{C}=\mathrm{N}$ groups, benzene rings, methyl and hydroxyl functional groups. PSC_1 and PSC_2 have the highest percentage inhibition efficiency. This is due to the large size of antipyrine category which makes better surface coverage and hence the highest inhibition efficiency is obtained. PSC_ 1 displays the highest inhibition efficiency; this is due to the presence of additional 
benzene ring in its structure which enhances the electron density on the inhibitor in addition to its higher molecular area. IE (\%) of PSC_3 is higher than that of PSC_4, due to the presence of an additional benzene ring in the arylidene part of the additive, which increases the area of the adsorbed molecule and consequently makes better surface coverage on the metal surface than in the case of the other additives PSC_4 and PSC_5. IE (\%) of PSC_4 is higher than that of compound PSC_5, which can be explained on the basis that the basic strength of the $\mathrm{C}=\mathrm{N}$ group is insufficient to permit the formation of stable complex through a simple coordination bond with the metal ion through the lone pair of the nitrogen atom. Therefore, a functional group with a replaceable hydrogen ion $(\mathrm{OH}$ group) in the ortho position of PSC_4 enhances the formation of a stable chelate complex with the corroding metal ions. Consequently, both the Schiff base inhibitor and Schiff base-metal complexes (Fig. 2) can be adsorbed or deposited on the iron surface, hence causing an additional inhibition of iron corrosion [78]. Finally, PSC_5 comes at the end of all the investigated PSC compounds in its percentage inhibition efficiency value, owing to the presence of $\mathrm{OH}$ group in the para position. The adsorption process of PSC molecules on the metal surface interferes with the adsorption of the anions [68] present in the corrosive media. The anodic dissolution of iron follows the steps [79]:

$$
\begin{aligned}
& \mathrm{Fe}+\mathrm{NO}_{3}^{-} \rightleftarrows\left(\mathrm{FeNO}_{3}^{-}\right)_{\mathrm{ads}} \\
& \left(\mathrm{FeNO}_{3}^{-}\right)_{\mathrm{ads}} \rightleftarrows\left(\mathrm{FeNO}_{3}^{-}\right)_{\mathrm{ads}}+\mathrm{e}^{-} \\
& \left(\mathrm{FeNO}_{3}^{-}\right)_{\mathrm{ads}} \rightleftarrows\left(\mathrm{FeNO}_{3}^{+}\right)+\mathrm{e}^{-} \\
& \left(\mathrm{FeNO}_{3}^{+}\right) \rightleftarrows \mathrm{Fe}^{2+}+\mathrm{NO}_{3}^{-}
\end{aligned}
$$

Schiff bases have basic character and expected to be protonated in equilibrium with the corresponding neutral form in strong acid solutions.

$\mathrm{PSC}+\mathrm{H}^{+} \rightleftarrows \mathrm{PSCH}^{+}$

Because iron surface carried positive charge, $\mathrm{NO}_{3}{ }^{-}$ions should be first adsorbed onto the positively charged metal surface according to reaction (22). Then, the inhibitor molecules adsorb through electrostatic interactions between the negatively charged metal surface and positively charged Schiff base molecule ( $\mathrm{PSCH}^{+}$) and form a protective $\left(\mathrm{FeNO}_{3}{ }^{-} \mathrm{PSCH}^{+}\right)_{\text {ads }}$ layer. In this way, the oxidation reaction of $\left(\mathrm{FeNO}_{3}{ }^{-}\right)_{\text {ads }}$ as shown by reaction steps from (23) to (25) can be prevented [80, 81]. During the corrosion of iron in strong acid solution, the cathodic reaction is reduction of $\mathrm{H}^{+}$ions to molecular hydrogen according to reaction mechanism given below $[79,80]$ :

$$
\begin{aligned}
& \mathrm{Fe}+\mathrm{H}^{+} \rightleftarrows\left(\mathrm{FeH}^{+}\right)_{\mathrm{ads}} \\
& \left(\mathrm{FeH}^{+}\right)_{\mathrm{ads}}+\mathrm{e}^{-} \rightarrow(\mathrm{FeH})_{\mathrm{ads}} \\
& (\mathrm{FeH})_{\mathrm{ads}}+\mathrm{H}^{+}+\mathrm{e}^{-} \rightarrow \mathrm{Fe}+\mathrm{H}_{2}
\end{aligned}
$$

Because the rate of hydrogen gas evolution is directly proportional to the rate of corrosion, the measurement of hydrogen gas evolved at cathodic sites as a function of reaction time can give valuable information about starting and continuity of the corrosion. The relative speed and effectiveness of the gasometric techniques as well as their suitability for in situ monitoring, any perturbation by an inhibitor with respect to gas evolution in metal/solution system have been established in the literature $[82,83]$. The protonated Schiff base molecules are also adsorbed at cathodic sites of metal in competition with hydrogen ions according to Eq. (27). The adsorption of protonated Schiff base molecules reduces the rate of hydrogen evolution reaction [74, 79, 84]. In acidic solutions, the inhibitor can exist as cationic species (Eq. 30) which may be adsorbed on the cathodic sites of the iron and reduce the evolution of hydrogen:

$\mathrm{PSC}+2 \mathrm{H}^{+} \rightleftarrows[\mathrm{PSCH}]^{2+}$

The protonated PSC, however, could be attached to the iron surface by means of electrostatic interaction between $\mathrm{NO}_{3}{ }^{-}$and protonated PSC since the iron surface has positive charges in the acid medium [85]. This could further be explained based on the assumption that in the presence of $\mathrm{NO}_{3}{ }^{-}$, the negatively charged $\mathrm{NO}_{3}{ }^{-}$would attach to positively charged surface. When PSC adsorbs on the iron surface, electrostatic interaction takes place by partial transference of electrons from the polar atoms ( $\mathrm{N}$ and $\mathrm{O}$ atoms and the delocalized $\pi$-electrons around the heterocyclic rings) of PSC to the metal surface. In addition to electrostatic interaction (physisorption) of PSC molecules on the iron surface, molecular adsorption may also play a role in the adsorption process. A close examination of the chemical structure of PSCs reveals that PSC molecules have structure, characterized by the presence of chelation centers mainly located on nitrogen and oxygen. From theoretical and experimental results obtained, $\mathrm{N}$ and $\mathrm{O}$ atoms are the likely sites of complexation of PSC with the $\mathrm{Fe}^{2+}$ (Fig. 14) which will result in the formation of a five-membered, redox active $\alpha$-iminoketo chelate ring [86, 87]. The UV-visible absorption spectra (Fig. 2) of the solution containing the inhibitor after the immersion of the iron specimen indicated the formation of a complex with the iron surface allowing the formation of adhesive film. Such an adhesive film covered the metal surface isolating the metal surface from the corrosive media. Finally, it 
should also be emphasized that the large size and high molecular weight of Schiff base molecule can also contribute the greater inhibition efficiency of PSCs [6]. To present more details, the molecular orbital density distributions for five Schiff bases are shown. Figures 8 and 9 show that all the investigated Schiff bases (1-5) have very similar electronic density on their HOMO, so different inhibition effectiveness observed in five molecules cannot be explained in terms of $\mathrm{E}_{\mathrm{HOMO}}$. However, it can be found in Figs. 7 and 8 that the orbital density distributions on LUMO of Schiff bases are similar to each other and their only difference is related to orbital density distributions of LUMO that is localized over the atoms $\mathrm{N}$ and $\mathrm{O}$ and follows the following order: Schiff base_1 $>$ Schiff base_2 $>$ Schiff base_3 $>$ Schiff base_4 $>$ Schiff base_5 (Table 5). Finally, we remark that we do not know the real structure of Schiff base films; instead these arguments are used to demonstrate the differences in inhibition efficiency of these molecules. In general, the adsorption PSC molecules at the iron electrode surface depend on the molecular size, charge distribution and deformability of the active center as well as the charge on the metal surface undergoing corrosion. Thus, the increased formation of Schiff base-metal complexes leads to the formation of an insoluble film of the complex on the metal surface, which furnishes an additional inhibitive property to that of the investigated Schiff base inhibitors (PSCs) as shown in Fig. 14. Skeletal representation of the proposed mode of adsorption the investigated (PSCs) on iron surface is represented in Fig. 15.

\section{Conclusions}

Data obtained from quantum chemical calculations using DFT at the B3LYP/6-311++G** level of theory were correlated to the inhibitive effect of Schiff bases (PSCs). The relationships between inhibition efficiency of iron in aerated $2.0 \mathrm{M} \mathrm{HNO}_{3}$ and/or $2.0 \mathrm{M} \mathrm{NaOH}$ and the $E_{\mathrm{HOMO}}$, $E_{\mathrm{LUMO}}-E_{\mathrm{HOMO}}$, of PSCs were calculated by DFT method. The inhibition efficiency increased with the increase in $E_{\mathrm{HOMO}}$ and decrease in $E_{\mathrm{LUMO}}-E_{\mathrm{HOMO}}$. PSC_1 had the highest inhibition efficiency because it had the highest HOMO energy values, and it was most capable of offering electrons. The distribution of electronic density shows that the molecules of PSCs had many negatively charged active centers. The electron density was found to be positively correlated with length of aminic nitrogencontaining carbon bone chain, which was resulted in increase in inhibition efficiency. The areas containing $\mathrm{N}$ and $\mathrm{O}$ atoms are the most possible sites for bonding the metal iron surface by donating electrons to the metal. Experimental measurements and quantum theoretical<smiles></smiles><smiles></smiles>

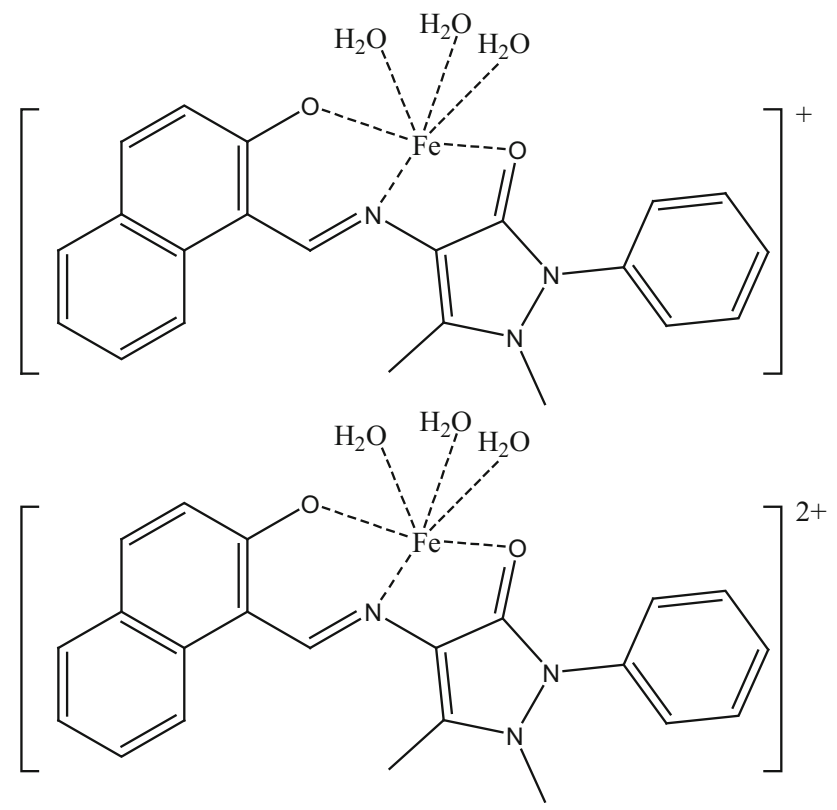

Fig. 14 Proposed structure of the complex compounds formed between PSC_1 and $\mathrm{Fe}^{2+}$

calculations are in excellent agreement. Inhibition efficiency is both concentration and immersion time dependent. The high IE (\%) of PSCs was attributed to the adherent adsorption of the inhibitor molecules on the iron surface, and the adsorption is spontaneous, exothermic, accompanied with a decrease in entropy of the system from thermodynamic point of view and obeys the Temkin isotherm. Polarization curves demonstrate that the examined Schiff bases behave as mixed type corrosion inhibitor in $\mathrm{HNO}_{3}$ and cathodic hydrogen evolution reactions. A firstorder kinetics relationship with respect to the iron was obtained with and without PSC from the kinetic treatment of the data. UV-visible spectrophotometric studies clearly 
<smiles>Cc1c(/N=C/c2c([C@@H](C)O)ccc3ccccc23)c(=O)n(-c2ccccc2)n1C</smiles>

4-(2-Hydroxynaphthylideneamino)antipyrine (1)<smiles></smiles>

4-(2-Hydroxybenzylideneamino)antipyrine (2)

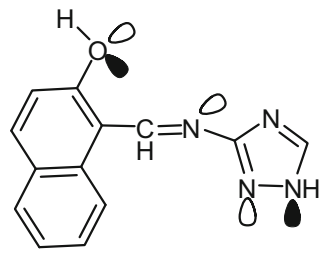

3-(2-Hydroxynaphthylideneamino)-1,2,4- triazole (3)

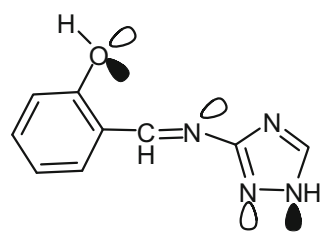

3-(2-Hydroxybenzylideneamino)-1,2,4- triazole (4)

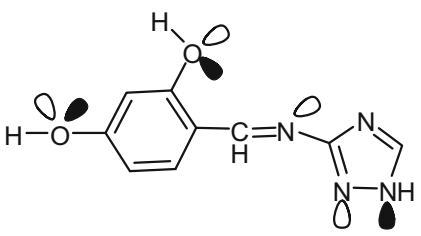

3-(4-Hydroxybenzylideneamino)-1,2,4- triazole (5)

Fig. 15 Skeletal representation of the proposed mode of adsorption the PSCs (1-5)

reveal the formation of Fe-PSC complex (Fig. 2) which may be enhanced for the observed inhibition process.

Acknowledgments I gratefully acknowledge Tanta University, Chemistry Department, at Tanta, Egypt for the financial assistance and Department of Chemistry, King Abdul-Aziz University, Jeddah, Saudi Arabia for facilitation of our study.

Open Access This article is distributed under the terms of the Creative Commons Attribution 4.0 International License (http:// creativecommons.org/licenses/by/4.0/), which permits unrestricted use, distribution, and reproduction in any medium, provided you give appropriate credit to the original author(s) and the source, provide a link to the Creative Commons license, and indicate if changes were made.

\section{References}

1. Álvarez-Bustamante R, Negrón-Silva G, Abreu-Quijano M, Herrera-Hernández H, Romero-Romo M, Cuán A, Palomar-Pardavé M (2009) Electrochemical study of 2-mercaptoimidazole as a novel corrosion inhibitor for steels. Electrochimica Acta 54(23):5393-5399

2. Ehteshamzadeh M, Jafari AH, Naderi E, Hosseini MG (2009) Effect of carbon steel microstructures and molecular structure of two new Schiff base compounds on inhibition performance in $1 \mathrm{M} \mathrm{HCl}$ solution by EIS. Mater Chem Phys 113(2-3):986-993

3. Behpour M, Ghoreishi SM, Soltani N, Salavati-Niasari M (2009) The inhibitive effect of some bis-N, S-bidentate Schiff bases on corrosion behaviour of 304 stainless steel in hydrochloric acid solution. Corrosion Sci 51(5):1073-1082

4. Emregül KC, Düzgün E, Atakol O (2006) The application of some polydentate Schiff base compounds containing aminic nitrogens as corrosion inhibitors for mild steel in acidic media. Corrosion Sci 48(10):3243-3260

5. Emregül KC, Atakol O (2003) Corrosion inhibition of mild steel with Schiff base compounds in $1 \mathrm{M} \mathrm{HCl}$. Mater Chem Phys 82(1):188-193

6. Behpour M, Ghoreishi SM, Salavati-Niasari M, Ebrahimi B (2008) Evaluating two new synthesized S-N Schiff bases on the corrosion of copper in 15\% hydrochloric acid. Mater Chem Phys 107(1):153-157

7. Asan A, Soylu S, Kiyak T, Yildirim F, Öztaş SG, Ancin N, Kabasakaloğlu M (2006) Investigation on some Schiff bases as corrosion inhibitors for mild steel. Corrosion Sci 48(12):3933-3944

8. Emregül KC, Atakol O (2004) Corrosion inhibition of iron in $1 \mathrm{M} \mathrm{HCl}$ solution with Schiff base compounds and derivatives. Mater Chem Phys 83(2-3):373-379

9. Yurt A, Ulutas S, Dal H (2006) Electrochemical and theoretical investigation on the corrosion of aluminium in acidic solution containing some Schiff bases. Appl Surf Sci 253(2):919-925

10. El Ashry ESH, El Nemr A, Esawy SA, Ragab S (2006) Corrosion inhibitors. Part II: quantum chemical studies on the corrosion inhibitions of steel in acidic medium by some triazole, oxadiazole and thiadiazole derivatives. Electrochimica Acta 51(19):3957-3968

11. Zhao P, Liang Q, Li Y (2005) Electrochemical, SEM/EDS and quantum chemical study of phthalocyanines as corrosion inhibitors for mild steel in $1 \mathrm{~mol} / \mathrm{l} \mathrm{HCl}$. Appl Surf Sci 252(5):1596-1607

12. Xiao-Ci Y, Hong Z, Ming-Dao L, Hong-Xuan R, Lu-An Y (2000) Quantum chemical study of the inhibition properties of pyridine and its derivatives at an aluminum surface. Corrosion Sci 42(4):645-653

13. Bereket G, Hür E, Öretir C (2002) Quantum chemical studies on some imidazole derivatives as corrosion inhibitors for iron in acidic medium. J Mol Struct (Thoechem) 578:79-88

14. Madkour LH, Zinhome UA (2010) J Corr Sci Eng (JCSE):13

15. Cukurovali A, Yilmaz I, Gur S, Kazaz C (2006) Synthesis, antibacterial and antifungal activity of some new thiazolylhydrazone derivatives containing 3-substituted cyclobutane ring. Eur J Med Chem 41(2):201-207

16. ASTM G 31-72 
17. Li XH, Deng SD, Mu GN, Fu H, Yang FZ (2008) Corros Sci 50:420-430

18. Li XH, Deng SD, Fu H, Mu GN (2008) Corros Sci 50:2635-2645

19. Vracar LM, Drazic DM (2002) Corros Sci 44:1669-1680

20. Mylius FZ (1922) Metallkunde 14:233

21. Aziz K, Shams El Din AM (1965) A simple method for the determination of the inhibition efficiency of surfactants. Corros Sci 5(7):489-501

22. Mylius FZ (1924) Eine kritische Zusammenfassung Metallkunde $16: 81$

23. Fouda AS, Elasmy AA (1987) Efficiency of some phenylthiosemicarbazide derivatives in retarding the dissolution of $\mathrm{Al}$ in $\mathrm{NaOH}$ solution. Monatshefte für Chemie Chem Monthly 118(6-7):709-716

24. Madkour LH, Elmorsi MA, Ghoneim MM (1995) Monatsh Chem 126:1087

25. Madkour LH, Ghoneim MM (1997) Bull Electrochem 13:1

26. Öğretir C, Mihçi B, Bereket G (1999) Quantum chemical studies of some pyridine derivatives as corrosion inhibitors. J Mol Struct (Thoechem) 488:223-231

27. Becke AD (1993) Density-functional thermochemistry. III. The role of exact exchange. J Chem Phys 98(7):5648-5652

28. Becke AD (1988) Density-functional exchange-energy approximation with correct asymptotic behavior. Phys Rev A 38(6):3098-3100. doi:10.1103/PhysRevA.38.3098

29. Lee C, Yang W, Parr RG (1988) Development of the ColleSalvetti correlation-energy formula into a functional of the electron density. Phys Rev B 37(2):785-789. doi:10.1103/Phys RevB.37.785

30. Frisch MJ, Trucks GW, Schlegel HB, Scuseria GE, Robb MAM, Cheeseman JR, Montgomery JA, Pople JA (2004) Supporting Information Inc. Gaussian, Wallingford, CT

31. Ferreira ES, Giancomelli C, Giacomelli FC, Spinelli A (2004) Mater Chem Phys 83:129-134

32. Li WH, He Q, Pei CL, Hou BR (2008) J Appl Electrochem 38:289-295

33. Sorkhabi HA, Shaabani B, Seifzadeh D (2005) Appl Surf Sci 239:154-164

34. Abdel-Rehim SS, Ibrahim MAM, Khaled KF (2001) Mater Chem Phys 70:268-273

35. Li X, Deng S, Fu H, Li T (2009) Adsorption and inhibition effect of 6-benzylaminopurine on cold rolled steel in $1.0 \mathrm{M} \mathrm{HCl}$. Electrochim Acta 54(16):4089-4098

36. Parr RG, Yang W (1984) Density functional approach to the frontier-electron theory of chemical reactivity. J Am Chem Soc 106(14):4049-4050

37. Fang J, Li J (2002) Quantum chemistry study on the relationship between molecular structure and corrosion inhibition efficiency of amides. J Mol Struct (Thoechem) 593:179-185

38. Lashkari M, Arshadi MR (2004) DFT studies of pyridine corrosion inhibitors in electrical double layer: solvent, substrate, and electric field effects. Chem Phys 299(1):131-137

39. Gece G, Bilgiç S (2010) A theoretical study on the inhibition efficiencies of some amino acids as corrosion inhibitors of nickel. Corros Sci 52(10):3435-3443

40. Lewis DFV, Ioannides C, Parke DV (1994) Interaction of a series of nitriles with the alcohol-inducible isoform of $\mathrm{p} 450$ : computer analysis of structure-activity relationships. Xenobiotica 24(5):401-408

41. Zhou Z, Parr RG (1990) Activation hardness: New index for describing the orientation of electrophilic aromatic substitution. J Am Chem Soc 112(15):5720-5724

42. Hohenberg P, Kohn W (1964) Inhomogeneous electron gas. Phys Rev 136(3B):B864-B871

43. Kikuchi O (1987) Struct Act Relat 6:179-184
44. Khaled KF, Fadl-Allah SA, Hammouti B (2009) Some benzotriazole derivatives as corrosion inhibitors for copper in acidic medium: experimental and quantum chemical molecular dynamics approach. Mater Chem Phys 117(1):148-155

45. Gece G (2008) The use of quantum chemical methods in corrosion inhibitor studies. Corros Sci 50(11):2981-2992

46. Parr RG, Szentpaly L, Liu S (1999) J Am Chem Soc 121:1922-1928

47. Chattaraj PK, Maiti B, Sarkar U (2003) Philicity: a unified treatment of chemical reactivity and selectivity. J Phys Chem A 107(25):4973-4975

48. Grüber C, Buß V (1989) Quantum-mechanically calculated properties for the development of quantitative structure-activity relationships (QSAR'S). pKA-values of phenols and aromatic and aliphatic carboxylic acids. Chemosphere 19(10-11): $1595-1609$

49. Abiola OK, Otaigbe JOE (2009) The effects of Phyllanthus amarus extract on corrosion and kinetics of corrosion process of aluminum in alkaline solution. Corros Sci 51(11):2790-2793

50. Ebbing DD, Gammon SD (2005) General Chemistry8/e. Houghton Mifflin, Boston

51. Abiola OK (2006) Adsorption of 3-(4-amino-2-methyl-5-pyrimidyl methyl)-4-methyl thiazolium chloride on mild steel. Corros Sci 48(10):3078-3090

52. Obi-Egbedi NO, Obot IB (2011) Inhibitive properties, thermodynamic and quantum chemical studies of alloxazine on mild steel corrosion in $\mathrm{H}_{2} \mathrm{SO}_{4}$. Corros Sci 53(1):263-275

53. Atkins P, de Paula J (2002) A Textbook of Physical Chemistry, seventh edn. University Press, Oxford, p 873

54. Quraishi MA, Rafiquee MZA, Khan S, Saxena N (2007) Corrosion inhibition of aluminium in acid solutions by some imidazoline derivatives. J Appl Electrochem 37(10):1153-1162

55. Bouklah M, Hammouti B, Lagrenée M, Bentiss F (2006) Thermodynamic properties of 2,5-bis(4-methoxyphenyl)-1,3,4-oxadiazole as a corrosion inhibitor for mild steel in normal sulfuric acid medium. Corrosion Science 48(9):2831-2842

56. Atkins PW (1998) Physical Chemistry, 6th edn. Oxford University Press, Oxford

57. Migahed MA (2005) Electrochemical investigation of the corrosion behaviour of mild steel in $2 \mathrm{M} \mathrm{HCl}$ solution in presence of 1-dodecyl-4-methoxy pyridinium bromide. Mater Chem Phys 93(1):48-53

58. Cases JM, Villieras F (1992) Thermodynamic model of ionic and nonionic surfactant adsorption-abstraction on heterogeneous surfaces. Langmuir 8(5):1251-1264

59. Tang L, Li X, Si Y, Mu G, Liu G (2006) The synergistic inhibition between 8-hydroxyquinoline and chloride ion for the corrosion of cold rolled steel in $0.5 \mathrm{M}$ sulfuric acid. Mater Chem Phys 95(1):29-38

60. Behpour M, Ghoreishi SM, Soltani N, Salavati-Niasari M, Hamadanian M, Gandomi A (2008) Electrochemical and theoretical investigation on the corrosion inhibition of mild steel by thiosalicylaldehyde derivatives in hydrochloric acid solution. Corros Sci 50(8):2172-2181

61. Sibel Z, Dogan P, Yazici B (2005) Corros Rev 23:217

62. Musa AY, Kadhum AAH, Mohamad AB, Daud AR, Takriff MS, Kamarudin SK (2009) A comparative study of the corrosion inhibition of mild steel in sulphuric acid by 4,4-dimethyloxazolidine-2-thione. Corros Sci 51(10):2393-2399

63. Benali O, Larabi L, Traisnel M, Gengembra L, Harek Y (2007) Appl Surf Sci 253:6130-6137

64. Noor EA, Al-Moubaraki AH (2008) Thermodynamic study of metal corrosion and inhibitor adsorption processes in mild steel/ 1-methyl-4[4'(-X)-styryl pyridinium iodides/hydrochloric acid systems. Mater Chem Phys 110(1):145-154 
65. Yadav DK, Maiti B, Quraishi MA (2010) Electrochemical and quantum chemical studies of 3,4-dihydropyrimidin-2(1H)-ones as corrosion inhibitors for mild steel in hydrochloric acid solution. Corros Sci 52(11):3586-3598

66. Badawy WA, Ismail KM, Fathi AM (2006) Corrosion control of $\mathrm{Cu}-\mathrm{Ni}$ alloys in neutral chloride solutions by amino acids. Electrochim Acta 51(20):4182-4189

67. Abdallah M (2002) Rhodanine azosulpha drugs as corrosion inhibitors for corrosion of 304 stainless steel in hydrochloric acid solution. Corros Sci 44(4):717-728

68. El-Awady AA, Abd-El-Nabey BA, Aziz SG, Khalifa M, AlGhamedy HA (1990) Int J Chem 1(4):169-179

69. El-Awady AA, Abd-El-Nabey BA, Aziz SG (1992) Kineticthermodynamic and adsorption isotherms analyses for the inhibition of the acid corrosion of steel by cyclic and open-chain amines. J Electrochem Soc 139(8):2149-2154

70. Frumkin AN (1925) Z Phys Chem 116:466-484

71. Fouda AS, Moussa MN, Taha FI, Elneanaa AI (1986) The role of some thiosemicarbazide derivatives in the corrosion inhibition of aluminium in hydrochloric acid. Corros Sci 26(9):719-726

72. Langmuir I (1918) The adsorption of gases on plane surfaces of glass, mica and platinum. J Am Chem Soc 40(9):1361-1403

73. Szkarska-Smialowska Z, Dus B (1967) Corrosion 23:130

74. Ahamad I, Prasad R, Quraishi MA (2010) Thermodynamic, electrochemical and quantum chemical investigation of some Schiff bases as corrosion inhibitors for mild steel in hydrochloric acid solutions. Corros Sci 52(3):933-942

75. Yurt A, Balaban A, Kandemir SU, Bereket G, Erk B (2004) Investigation on some Schiff bases as $\mathrm{HCl}$ corrosion inhibitors for carbon steel. Mater Chem Phys 85(2-3):420-426

76. Vračar LjM, Draži DM (2002) Adsorption and corrosion inhibitive properties of some organic molecules on iron electrode in sulfuric acid. Corr Sci 44(8):1669-1680

77. Soltani N, Behpour M, Ghoreishi SM, Naeimi H (2010) Corrosion inhibition of mild steel in hydrochloric acid solution by some double Schiff bases. Corros Sci 52(4):1351-1361
78. Hasanov R, Sadikoğlu M, Bilgiç S (2007) Electrochemical and quantum chemical studies of some Schiff bases on the corrosion of steel in $\mathrm{H}_{2} \mathrm{SO}_{4}$ solution. Appl Surf Sci 253(8):3913-3921

79. Shokry H, Sekine I, Yuasa M, El-Baradie HY, Comma GK, Issa RM (1997) Zairyo to Kankyo 47(7):447

80. Solmaz R, Kardaş G, Çulha M, Yazici B, Erbil M (2008) Investigation of adsorption and inhibitive effect of 2-mercaptothiazoline on corrosion of mild steel in hydrochloric acid media. Electrochim Acta 53(20):5941-5952

81. Zhang QB, Hua YX (2009) Corrosion inhibition of mild steel by alkylimidazolium ionic liquids in hydrochloric acid. Electrochim Acta 54(6):1881-1887

82. Solmaz R, Mert ME, Kardaş G, Yazici B, Erbil M (2008) Adsorption and Corrosion Inhibition Effect of 1,1' ${ }^{\prime}$-Thiocarbonyldiimidazole on Mild Steel in $\mathrm{H}_{2} \mathrm{SO}_{4}$ Solution and Synergistic Effect of Iodide Ion. Acta Phys Chim Sinica 24(7):1185-1191

83. Kaleş H, Keleş M, Dehri I, Serindag O (2008) The inhibitive effect of 6-amino-m-cresol and its Schiff base on the corrosion of mild steel in $0.5 \mathrm{M}$ HCI medium. Mater Chem Phys 112(1):173-179

84. Aytaç A, Özmen Ü, Kabasakaloğlu M (2005) Investigation of some Schiff bases as acidic corrosion of alloy AA3102. Mater Chem Phys 89(1):176-181

85. Solmaz R, Kardaş G, Yazici B, Erbil M (2008) Adsorption and corrosion inhibitive properties of 2-amino-5-mercapto-1,3,4thiadiazole on mild steel in hydrochloric acid media. Colloids Surf A Physicochem Eng Asp 312(1):7-17

86. Li Y, Zhao P, Liang Q, Hou B (2005) Berberine as a natural source inhibitor for mild steel in $1 \mathrm{M} \mathrm{H}_{2} \mathrm{SO}_{4}$. Appl Surf Sci 252(5):1245-1253

87. Kaim W, Schwederski B, Heilmann O, Hornung FM (1999) Coordination compounds of pteridine, alloxazine and flavin ligands: Structures and properties. Coord Chem Rev 182(1):323-342 